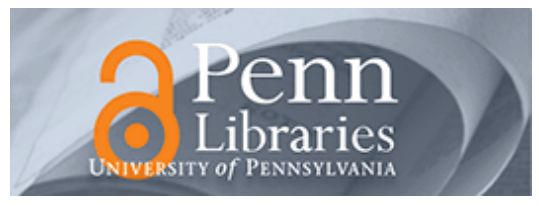

University of Pennsylvania

ScholarlyCommons

Marketing Papers

Wharton Faculty Research

2014

\title{
The Economics of Predation: What Drives Pricing When There is Learning-by-Doing?
}

David Besanko

Ulrich Doraszelski

University of Pennsylvania

Yaroslav Kryukov

Follow this and additional works at: https://repository.upenn.edu/marketing_papers

Part of the Behavioral Economics Commons, Labor Economics Commons, Marketing Commons, and the Public Economics Commons

\section{Recommended Citation}

Besanko, D., Doraszelski, U., \& Kryukov, Y. (2014). The Economics of Predation: What Drives Pricing When There is Learning-by-Doing?. American Economic Review, 104 (3), 868-897. http://dx.doi.org/10.1257/ aer.104.3.868

This paper is posted at ScholarlyCommons. https://repository.upenn.edu/marketing_papers/422

For more information, please contact repository@pobox.upenn.edu. 


\title{
The Economics of Predation: What Drives Pricing When There is Learning-by- Doing?
}

\author{
Abstract \\ We formally characterize predatory pricing in a modern industry-dynamics framework that endogenizes \\ competitive advantage and industry structure. As an illustrative example we focus on learning-by-doing. \\ To disentangle predatory pricing from mere competition for efficiency on a learning curve we decompose \\ the equilibrium pricing condition. We show that forcing firms to ignore the predatory incentives in setting \\ their prices can have a large impact and that this impact stems from eliminating equilibria with predation- \\ like behavior. Along with predation-like behavior, however, a fair amount of competition for the market is \\ eliminated.

\section{Disciplines} \\ Behavioral Economics | Business | Labor Economics | Marketing | Public Economics
}




\title{
The Economics of Predation: What Drives Pricing When There Is Learning-by-Doing?
}

\author{
By David Besanko, Ulrich Doraszelski, and Yaroslav Kryukov*
}

We formally characterize predatory pricing in a modern industrydynamics framework that endogenizes competitive advantage and industry structure. As an illustrative example we focus on learningby-doing. To disentangle predatory pricing from mere competition for efficiency on a learning curve we decompose the equilibrium pricing condition. We show that forcing firms to ignore the predatory incentives in setting their prices can have a large impact and that this impact stems from eliminating equilibria with predationlike behavior. Along with the predation-like behavior, however, a fair amount of competition for the market is eliminated. (JEL D21, D43, D83, K21, L13, L41)

Predatory pricing - a deliberate strategy of pricing aggressively in order to eliminate competitors-is one of the more contentious areas of antitrust policy. Scholars such as Edlin (2012) argue that predatory pricing can, under certain circumstances, be a profitable business strategy. Others-commonly associated with the Chicago School-suggest that predatory pricing is rarely rational and thus unlikely to be practiced or, as Baker (1994) puts it, somewhere between a white tiger and a unicorn - a rarity and a myth.

At the core of predatory pricing is a trade-off between lower profit in the short run due to aggressive pricing and higher profit in the long run due to reduced competition. But as the debate over the efficacy — and even the existence — of predatory pricing suggests, it is not necessarily straightforward to translate this intuitive understanding into a more precise characterization of what predatory pricing actually is..$^{1}$

\footnotetext{
* Besanko: Kellogg School of Management, Northwestern University, 2001 Sheridan Road, Evanston, IL 60208 (e-mail: d-besanko@kellogg.northwestern.edu); Doraszelski: Wharton School, University of Pennsylvania, 3620 Locust Walk, Philadelphia, PA 19104 (e-mail: doraszelski@wharton.upenn.edu); Kryukov: Tepper School of Business, Carnegie Mellon University, 5000 Forbes Avenue, Pittsburgh, PA 15213 (e-mail: kryukov@ cmu.edu). We thank Lanier Benkard, Luis Cabral, Chiara Fumagalli, Dan Gottlieb, Joe Harrington, Ken Hendricks, Ariel Pakes, Mike Riordan, Mark Satterthwaite, and Connan Snider as well as two anonymous referees for helpful discussions and suggestions. We also thank participants at the 2010 Searle Center Conference on Antitrust Economics and Competition Policy, the Ninth Annual International Industrial Organization Conference, and the 2011 NYU Stern IO Day for their useful questions and comments. Most computations have been done on the Wharton School Grid and we are indebted to Hugh MacMullan for technical support. Besanko and Doraszelski gratefully acknowledge financial support from the National Science Foundation under Grant 0615615. The authors declare that they have no relevant or material financial interests that relate to the research described in this paper.

${ }^{\dagger}$ Go to http://dx.doi.org/10.1257/aer.104.3.868 to visit the article page for additional materials and author disclosure statement(s).

${ }^{1}$ Edlin (2002) provides a comprehensive overview of the current law on predatory pricing. Bolton, Brodley, and Riordan (2000) and Edlin (2012) provide excellent reviews of the theoretical and empirical literature.
} 
Characterizing predatory pricing is especially complicated when firms face other intertemporal trade-offs such as learning-by-doing, network effects, or switching costs that can give rise to aggressive pricing with subsequent recoupment. ${ }^{2}$ The empirical literature, in particular, provides ample evidence that the marginal cost of production decreases with cumulative experience in a variety of industrial settings, ${ }^{3}$ and the resulting tension between predatory pricing and mere competition for efficiency on a learning curve often comes to the fore when predation is alleged. It was, for example, a key issue in the policy debate about the "semiconductor wars" between the United States and Japan during the 1970s and 1980s (Flamm 1993, 1996; Dick 1991). Similarly, the predatory pricing that US color television producers accused Japanese producers of during the 1960s and 1970s may have reflected a strategy of acquiring competitive advantage by exploiting learning economies (Yamamura and Vandenberg 1986). The European Commission case against Intel in 2009 over the use of loyalty reward payments to computer manufacturers (that lead to a recordbreaking fine of $\$ 1.5$ billion) likewise revolved around whether Intel's behavior was exclusionary or efficiency enhancing (Willig, Orszag, and Levin 2009).4

While predatory pricing is difficult to disentangle from pricing aggressively to pursue efficiency, being able to do so is important in legal cases involving alleged predation. Moreover, if one entertains the possibility that predatory pricing is a viable business strategy, then a characterization of predatory pricing is required to allow economists, legal scholars, and antitrust practitioners to detect its presence and measure its extent.

The purpose of this paper is to formally characterize predatory pricing in a modern industry-dynamics framework along the lines of Ericson and Pakes (1995). To this end, we develop a dynamic pricing model with endogenous competitive advantage and industry structure. The model is general enough to embrace a number of specific applications including learning-by-doing, network effects, switching costs, dynamic demand, and certain types of adjustment costs. As an illustration of our general model, we focus on learning-by-doing as a special case.

We ask three interrelated questions. First, what drives pricing and, specifically, how can we separate predatory incentives for pricing aggressively from efficiencyenhancing incentives? Second, when does predation-like behavior arise? Third, what is the impact of the predatory incentives on industry structure, conduct, and performance?

What Drives Pricing? - Unlike much of the previous literature, we do not attempt to deliver an ironclad definition of predation. Instead, our contribution is to show that we can isolate a firm's predatory incentives by analytically decomposing the

\footnotetext{
${ }^{2}$ This point has been made previously by Farrell and Katz (2005, p. 204): "Distinguishing competition from predation is even harder in network markets than in others. With intertemporal increasing returns, there may innocently be intense initial competition as firms fight to make initial sales and benefit from the increasing returns."

${ }^{3}$ See the references in footnote 2 of Besanko et al. (2010).

${ }^{4}$ For example, Intel CEO Paul Otellini argued "[w]e have however, ... consistently invested in innovation, in manufacturing and in developing leadership technology. The result is that we can discount our products to compete in a highly competitive marketplace, passing along to consumers everywhere the efficiencies of being the world's leading volume manufacturer of microprocessors." Andrew Nusca, "EC: Intel 'Abused Dominant Position' vs AMD; Fined Record \$1.45 Billion in Antitrust Case," Between the Lines (blog), ZDNet, May 13, 2009, http://www. zdnet.com/blog/btl/ec-intel-abused-dominant-position-vs-amd-fined-record-145-billion-in-antitrust-case/17884 (accessed June 7, 2011).
} 
equilibrium pricing condition. Our decomposition is reminiscent of that of Ordover and Saloner (1989) but extends to the complex strategic interactions that arise in the Markov perfect equilibrium of a dynamic stochastic game.

The cornerstone of our decomposition is the insight that, in a dynamic pricing model with endogenous competitive advantage and industry structure, the price set by a firm reflects two goals besides short-run profit. First, by pricing aggressively, the firm may improve its competitive position in the future, giving rise to what we call the advantage-building motive. Second, the firm may prevent its rival from becoming a more formidable competitor, giving rise to the advantage-denying motive.

Our decomposition corresponds to the common practice of antitrust authorities to question the intent behind a business strategy: Is the firm's aggressive pricing behavior primarily driven by the benefits of acquiring competitive advantage or by the benefits from preventing the rival from acquiring competitive advantage or overcoming competitive disadvantage? The advantage-building motive maps into the first set of benefits and the advantage-denying motive into the second set.

Due to its prominent role in predation cases, we examine learning-by-doing in more detail in a model similar to those in Cabral and Riordan (1994) and Besanko et al. (2010). Decomposing the equilibrium pricing condition with even more granularity reveals that the probability that the rival exits the industry- the linchpin of any notion of predatory pricing - affects both the advantage-building and advantage-denying motives. One component of the advantage-building motive is the advantage-building/exit motive. This is the marginal benefit to the firm from the increase in the probability of rival exit that results if the firm moves further down its learning curve. Similarly, the advantage-denying/exit motive is the marginal benefit from preventing the decrease in the probability of rival exit that results if the rival moves further down its learning curve.

Our decomposition provides us with a coherent and flexible way to define a firm's predatory pricing incentives. Although our three alternative definitions are motivated by the existing literature, they draw the line between predatory pricing and mere competition for efficiency on a learning curve in different places. Indeed, our decomposition makes clear that there is much latitude in where exactly to draw this line.

When Does Predation-Like Behavior Arise?-While there is a sizeable literature that attempts to rationalize predatory pricing as an equilibrium phenomenon by means of reputation effects (Kreps et al. 1982), informational asymmetries (Fudenberg and Tirole 1986), or financial constraints (Bolton and Sharfstein 1990), our learning-bydoing model forgoes these features and "stacks the deck" against predatory pricing. Our numerical analysis nevertheless reveals the widespread existence of equilibria involving behavior that resembles conventional notions of predatory pricing in the sense that aggressive pricing in the short run is associated with reduced competition in the long run. The fact that predation-like behavior arises routinely and without requiring extreme or unusual parameterizations calls into question the idea that economic theory provides prima facie evidence that predatory pricing is a rare phenomenon.

Our paper relates to earlier work by Cabral and Riordan (1994), who establish analytically the possibility that predation-like behavior can arise in a model of learning-by-doing, and Snider (2008), who uses the Ericson and Pakes (1995) framework to explore whether American Airlines engaged in predatory capacity 
expansion in the Dallas-Fort Worth to Wichita market in the late 1990s. We go beyond establishing possibility by way of an example or a case study and show just how common predation-like behavior is.

We also reinforce and formalize a point made by Edlin (2012, p. 147) that predatory pricing is common "if business folk think so." Equilibria involving predation-like behavior often coexist in our model with equilibria involving much less aggressive pricing. Multiple equilibria arise in our model if, for given demand and cost fundamentals, there is more than one set of firms' expectations regarding the value of continued play that is consistent with rational expectations about equilibrium behavior and industry dynamics. ${ }^{5}$ Which of these equilibria is realized depends on firms' expectations. Loosely speaking, if firms anticipate that predatory pricing may work, they have an incentive to choose the extremely aggressive prices that, in turn, ensure that predatory pricing does work. Guiding firms' expectations regarding the evolution of the industry can thus be a powerful tool for antitrust policy.

In providing a formal connection between predatory pricing and multiple equilibria, our paper relates to independent work by Shalem, Spiegel, and Stahl (2011). Their model admits an equilibrium in which a strong firm prices aggressively to drive a weak firm out of the market and another equilibrium in which the strong firm accommodates its current competitor as well as all subsequent entrants. In contrast to our model, competitive advantage is exogenous in their model and aggressive pricing is predatory by default (as it cannot improve a firm's competitive position).

What Is the Impact of Predatory Incentives?-While much of the previous literature has argued for-or against — the merits of particular definitions of predation on conceptual grounds, we directly measure the impact of a firm's predatory pricing incentives (according to the various definitions) on industry structure, conduct, and performance. We do so by computing equilibria of a counterfactual game in which firms ignore the predatory incentives in setting their prices and comparing them to equilibria of the actual game across a wide range of parameterizations.

Ignoring the advantage-building/exit and advantage-denying/exit motives in line with our narrowest definition of predatory incentives has on average a smaller impact on industry structure, conduct, and performance than ignoring the advantage-building and advantage-denying motives in their entirety in line with our broadest definition of predatory incentives. Ignoring more broadly defined predatory incentives has a larger impact because it eliminates equilibria with predation-like behavior, paving the way for lower concentration and prices and higher consumer and total surplus in the long run. In contrast, it causes little change in equilibria involving less aggressive pricing.

Our analysis further reveals a tension between reducing predation-like behavior and reducing the intense competition for the market that gives rise to high levels of consumer surplus in the short run. Indeed, the price of making future consumers better off is often to make current consumers worse off. The price to be paid can be very steep for the broadest definition of predatory incentives.

\footnotetext{
${ }^{5}$ Multiple equilibria can potentially also arise in our model if the best replies of the one-shot game that is being played given continuation values intersect more than once. This cannot happen in the model in Besanko et al. (2010).
} 


\section{Model}

Because predatory pricing is an inherently dynamic phenomenon, we consider a discrete-time, infinite-horizon dynamic stochastic game between two firms. We first lay out a general dynamic pricing model with endogenous competitive advantage and industry structure that gives rise to an advantage-building and an advantage-denying motive and then tailor the model to an industry with learning-by-doing.

\section{A. Setup}

At any point in time, firm $n \in\{1,2\}$ is described by its state $e_{n} \in\{0,1, \ldots, M\}$. A firm in state $e_{n}=0$ is a potential entrant, and a firm in state $e_{n} \in\{1, \ldots, M\}$ is an incumbent firm that competes in the product market and jostles for competitive advantage. State $e_{n} \in\{1, \ldots, M\}$ is the competitive position of incumbent firm $n$ and indicates the level of a valuable firm-specific resource such as a cost or demand advantage. In an industry with learning-by-doing, for example, state $e_{n} \in\{1, \ldots, M\}$ indicates the cumulative experience or stock of know-how of incumbent firm $n$ which, in turn, determines its production cost. With network effects or switching costs, it indicates the installed base or the number of captive customers.

The industry's state is the vector of firms' states $\mathbf{e}=\left(e_{1}, e_{2}\right) \in\{0,1, \ldots, M\}^{2}$. In each period, firms first set prices and then decide on exit and entry. During the price-setting phase the industry's state changes from $\mathbf{e}$ to $\mathbf{e}^{\prime}$ depending on the pricing decisions of the incumbent firms. During the exit-entry phase, the state further changes from $\mathbf{e}^{\prime}$ to $\mathbf{e}^{\prime \prime}$ depending on the exit decisions of the incumbent firms and the entry decisions of the potential entrants. The state at the end of the current period finally becomes the state at the beginning of the subsequent period.

Product Market and Competitive Advantage.-As incumbent firm $n$ competes in the product market, its profit in the current period is $\pi_{n}(\mathbf{p}, \mathbf{e})$ given the vector of firms' prices $\mathbf{p}=\left(p_{1}, p_{2}\right)$ and the industry's state $\mathbf{e} .^{6}$

Besides competing in the product market, incumbent firm $n$ adjusts its price in the current period to influence the industry's state in the subsequent period. Competitive advantage is therefore determined endogenously. Specifically, we model the probability that the industry's state changes from $\mathbf{e}$ to $\mathbf{e}^{\prime}$ during the price-setting phase as $\operatorname{Pr}\left(\mathbf{e}^{\prime} \mid \mathbf{e}, \mathbf{q}\right)$ given the vector $\mathbf{q}=\left(q_{1}, q_{2}\right)$ and the industry's state $\mathbf{e}$, where $q_{n}$ $=D_{n}(\mathbf{p}, \mathbf{e})$ is itself a function of prices $\mathbf{p}$ and the industry's state $\mathbf{e}$. It is natural to think of $\mathbf{q}$ as (realized or expected) quantities or market shares and of $D_{n}(\cdot)$ as the demand function of incumbent firm $n$, but $\mathbf{q}$ can actually be anything resulting from the pricing decisions of the incumbent firms such as the probability of making a sale or the profit from competing in the product market.

Exit and Entry.-We model entry as a transition from state $e_{n}^{\prime}=0$ to state $e_{n}^{\prime \prime}=1$ and exit as a transition from state $e_{n}^{\prime} \geq 1$ to state $e_{n}^{\prime \prime}=0$ so that the exit of an

\footnotetext{
${ }^{6}$ To conserve on notation, we take the price of a potential entrant to be infinity.
} 
incumbent firm creates an opportunity for a new firm to enter the industry. Re-entry is therefore possible.

If incumbent firm $n$ exits the industry, it receives a scrap value $X_{n}$ drawn from a symmetric triangular distribution $F_{X}(\cdot)$ with support $\left[\bar{X}-\Delta_{X}, \bar{X}+\Delta_{X}\right]$, where $E_{X}\left(X_{n}\right)=\bar{X}$ and $\Delta_{X}>0$ is a scale parameter. If potential entrant $n$ enters the industry, it incurs a setup cost $S_{n}$ drawn from a symmetric triangular distribution $F_{S}(\cdot)$ with support $\left[\bar{S}-\Delta_{S}, \bar{S}+\Delta_{S}\right]$, where $E_{S}\left(S_{n}\right)=\bar{S}$ and $\Delta_{S}>0$ is a scale parameter. Scrap values and setup costs are independently and identically distributed across firms and periods, and their realization is observed by the firm but not its rival.

\section{B. Firms' Decisions}

To analyze the pricing and exit decisions of incumbent firms and the entry decision of a potential entrant, we work backwards from the exit-entry phase to the price-setting phase. Because scrap values and setup costs are private to a firm, its rival remains uncertain about the firm's decision. Combining exit and entry decisions, we let $\phi_{n}\left(\mathbf{e}^{\prime}\right)$ denote the probability, as viewed from the perspective of its rival, that firm $n$ decides not to operate in state $\mathbf{e}^{\prime}$.

We let $V_{n}(\mathbf{e})$ denote the expected net present value (NPV) of future cash flows to firm $n$ in state e at the beginning of the period and $U_{n}\left(\mathbf{e}^{\prime}\right)$ the expected NPV of future cash flows to firm $n$ in state $\mathbf{e}^{\prime}$ after pricing decisions but before exit and entry decisions are made. The price-setting phase determines the value function $V_{n}(\mathbf{e})$ along with the policy function $p_{n}(\mathbf{e})$; the exit-entry phase determines the value function $U_{n}\left(\mathbf{e}^{\prime}\right)$ along with the policy function $\phi_{n}\left(\mathbf{e}^{\prime}\right)$.

Exit Decision of Incumbent Firm.-To simplify the exposition, we focus on firm 1; the derivations for firm 2 are analogous. If incumbent firm 1 exits the industry, it receives the scrap value $X_{1}$ in the current period and perishes. If it does not exit, its expected NPV is

$$
\widehat{X}_{1}\left(\mathbf{e}^{\prime}\right)=\beta\left[V_{1}\left(\mathbf{e}^{\prime}\right)\left(1-\phi_{2}\left(\mathbf{e}^{\prime}\right)\right)+V_{1}\left(e_{1}^{\prime}, 0\right) \phi_{2}\left(\mathbf{e}^{\prime}\right)\right],
$$

where $\beta \in[0,1)$ is the discount factor. Incumbent firm 1's decision to exit the industry in state $\mathbf{e}^{\prime}$ is thus $\phi_{1}\left(\mathbf{e}^{\prime}, X_{1}\right)=1\left[X_{1} \geq \widehat{X}_{1}\left(\mathbf{e}^{\prime}\right)\right]$, where $1[\cdot]$ is the indicator function and $\widehat{X}_{1}\left(\mathbf{e}^{\prime}\right)$ the critical level of the scrap value above which exit occurs. The probability of incumbent firm 1 exiting is $\phi_{1}\left(\mathbf{e}^{\prime}\right)=1-F_{X}\left(\widehat{X}_{1}\left(\mathbf{e}^{\prime}\right)\right)$, and before incumbent firm 1 observes its draw of the scrap value, its expected NPV is given by the Bellman equation,

$$
\begin{aligned}
U_{1}\left(\mathbf{e}^{\prime}\right)= & E_{X}\left[\max \left\{\widehat{X}_{1}\left(\mathbf{e}^{\prime}\right), X_{1}\right\}\right] \\
= & \left(1-\phi_{1}\left(\mathbf{e}^{\prime}\right)\right) \beta\left[V_{1}\left(\mathbf{e}^{\prime}\right)\left(1-\phi_{2}\left(\mathbf{e}^{\prime}\right)\right)+V_{1}\left(e_{1}^{\prime}, 0\right) \phi_{2}\left(\mathbf{e}^{\prime}\right)\right] \\
& +\phi_{1}\left(\mathbf{e}^{\prime}\right) E_{X}\left[X_{1} \mid X_{1} \geq \widehat{X}_{1}\left(\mathbf{e}^{\prime}\right)\right]
\end{aligned}
$$


where $E_{X}\left[X_{1} \mid X_{1} \geq \widehat{X}_{1}\left(\mathbf{e}^{\prime}\right)\right]$ is the expectation of the scrap value conditional on exiting the industry.

Entry Decision of Potential Entrant.-If potential entrant 1 does not enter the industry, it perishes. If it enters and becomes an incumbent firm (in the initial state 1) in the subsequent period, its expected NPV is

$$
\widehat{S}_{1}\left(\mathbf{e}^{\prime}\right)=\beta\left[V_{1}\left(1, e_{2}^{\prime}\right)\left(1-\phi_{2}\left(\mathbf{e}^{\prime}\right)\right)+V_{1}(1,0) \phi_{2}\left(\mathbf{e}^{\prime}\right)\right]
$$

In addition, it incurs the setup cost $S_{1}$ in the current period. Potential entrant 1's decision to not enter the industry in state $\mathbf{e}^{\prime}$ is thus $\phi_{1}\left(\mathbf{e}^{\prime}, S_{1}\right)=1\left[S_{1} \geq \widehat{S}_{1}\left(\mathbf{e}^{\prime}\right)\right]$, where $\widehat{S}_{1}\left(\mathbf{e}^{\prime}\right)$ is the critical level of the setup cost. The probability of potential entrant 1 not entering is $\phi_{1}\left(\mathbf{e}^{\prime}\right)=1-F_{S}\left(\widehat{S}_{1}\left(\mathbf{e}^{\prime}\right)\right)$, and before potential entrant 1 observes its draw of the setup cost, its expected NPV is given by the Bellman equation

$$
\begin{aligned}
& U_{1}\left(\mathbf{e}^{\prime}\right)=E_{S}\left[\max \left\{\hat{S}_{1}\left(\mathbf{e}^{\prime}\right)-S_{1}, 0\right\}\right] \\
&=\left(1-\phi_{1}\left(\mathbf{e}^{\prime}\right)\right)\left\{\beta\left[V_{1}\left(1, e_{2}^{\prime}\right)\left(1-\phi_{2}\left(\mathbf{e}^{\prime}\right)\right)+V_{1}(1,0) \phi_{2}\left(\mathbf{e}^{\prime}\right)\right]\right. \\
&\left.-E_{S}\left[S_{1} \mid S_{1} \leq \widehat{S}_{1}\left(\mathbf{e}^{\prime}\right)\right]\right\}
\end{aligned}
$$

where $E_{S}\left[S_{1} \mid S_{1} \leq \widehat{S}_{1}\left(\mathbf{e}^{\prime}\right)\right]$ is the expectation of the setup cost conditional on entering the industry. 7

Pricing Decision of Incumbent Firm.-In the price-setting phase, the expected NPV of incumbent firm 1 is

$$
\begin{aligned}
V_{1}(\mathbf{e})= & \max _{p_{1}} \pi_{1}\left(p_{1}, p_{2}(\mathbf{e}), \mathbf{e}\right) \\
& +\sum_{\mathbf{e}^{\prime}} U_{1}\left(\mathbf{e}^{\prime}\right) \operatorname{Pr}\left(\mathbf{e}^{\prime} \mid \mathbf{e}, D_{1}\left(p_{1}, p_{2}(\mathbf{e}), \mathbf{e}\right), D_{2}\left(p_{1}, p_{2}(\mathbf{e}), \mathbf{e}\right)\right)
\end{aligned}
$$

Because $\sum_{\mathbf{e}^{\prime}} \operatorname{Pr}\left(\mathbf{e}^{\prime} \mid \mathbf{e}, \mathbf{q}\right)=1$, we can formulate the maximization problem on the right-hand side of the Bellman equation (3) as $\max _{p_{1}} \Pi_{1}\left(p_{1}, p_{2}(\mathbf{e}), \mathbf{e}\right)$, where

$$
\begin{aligned}
\Pi_{1}\left(p_{1}, p_{2}(\mathbf{e}), \mathbf{e}\right)= & \pi_{1}\left(p_{1}, p_{2}(\mathbf{e}), \mathbf{e}\right)+U_{1}(\mathbf{e})+\sum_{\mathbf{e}^{\prime} \neq \mathbf{e}}\left[U_{1}\left(\mathbf{e}^{\prime}\right)-U_{1}(\mathbf{e})\right] \\
& \times \operatorname{Pr}\left(\mathbf{e}^{\prime} \mid \mathbf{e}, D_{1}\left(p_{1}, p_{2}(\mathbf{e}), \mathbf{e}\right), D_{2}\left(p_{1}, p_{2}(\mathbf{e}), \mathbf{e}\right)\right)
\end{aligned}
$$

is the long-run profit of incumbent firm 1. The first-order condition for the pricing decision $p_{1}(\mathbf{e})$ of incumbent firm 1 is

\footnotetext{
${ }^{7}$ See the online Appendix for closed-form expressions for $E_{X}\left[X_{1} \mid X_{1} \geq \widehat{X}_{1}\left(\mathbf{e}^{\prime}\right)\right]$ in equation (1) and $E_{S}\left[S_{1} \mid S_{1} \leq \widehat{S}_{1}\left(\mathbf{e}^{\prime}\right)\right]$ in equation (2).
} 


$$
\begin{aligned}
0= & \frac{\partial \pi_{1}\left(p_{1}, p_{2}(\mathbf{e}), \mathbf{e}\right)}{\partial p_{1}} \\
& +\sum_{\mathbf{e}^{\prime} \neq \mathbf{e}}\left[U_{1}\left(\mathbf{e}^{\prime}\right)-U_{1}(\mathbf{e})\right] \frac{\partial \operatorname{Pr}\left(\mathbf{e}^{\prime} \mid \mathbf{e}, D_{1}\left(p_{1}, p_{2}(\mathbf{e}), \mathbf{e}\right), D_{2}\left(p_{1}, p_{2}(\mathbf{e}), \mathbf{e}\right)\right)}{\partial q_{1}} \frac{\partial D_{1}\left(p_{1}, p_{2}(\mathbf{e}), \mathbf{e}\right)}{\partial p_{1}} \\
& +\sum_{\mathbf{e}^{\prime} \neq \mathbf{e}}\left[U_{1}(\mathbf{e})-U_{1}\left(\mathbf{e}^{\prime}\right)\right] \frac{\partial \operatorname{Pr}\left(\mathbf{e}^{\prime} \mid \mathbf{e}, D_{1}\left(p_{1}, p_{2}(\mathbf{e}), \mathbf{e}\right), D_{2}\left(p_{1}, p_{2}(\mathbf{e}), \mathbf{e}\right)\right)}{\partial q_{2}} \frac{\partial\left(-D_{2}\right)\left(p_{1}, p_{2}(\mathbf{e}), \mathbf{e}\right)}{\partial p_{1}},
\end{aligned}
$$

where in the last line we take the derivative of $\left(-D_{2}\right)\left(p_{1}, p_{2}(\mathbf{e})\right)$ instead of $D_{2}\left(p_{1}, p_{2}(\mathbf{e})\right)$ with respect to $p_{1}$ to make the sign comparable to that of the derivative of $D_{1}\left(p_{1}, p_{2}(\mathbf{e})\right)$.

The pricing decision $p_{1}(\mathbf{e})$ of incumbent firm 1 is akin to an investment decision in that it encompasses its short-run profit $\pi_{1}\left(p_{1}, p_{2}(\mathbf{e}), \mathbf{e}\right)$ and its long-run competitive position vis-à-vis that of its rival. Competitive advantage changes as the industry's state changes. Equation (5) shows that the firm's price $p_{1}$ affects the transitions in the industry's state from e to $\mathbf{e}^{\prime}$ through two distinct channels: first, through the impact that $p_{1}$ has on the firm's quantity $q_{1}$ and, second, through the impact that $p_{1}$ has on its rival's quantity $q_{2}$. We call the first channel the advantage-building motive and the second channel the advantage-denying motive. Loosely speaking, the advantage-building motive captures the idea that a lower price $p_{1}$ may-by way of a higher quantity $q_{1}$ —change the industry's state in a way that is more favorable to incumbent firm 1 . The advantage-denying motive captures the idea that a lower price $p_{1}$ may - by way of a lower quantity $q_{2}$-prevent the industry's state from changing in a way that is less favorable to incumbent firm 1.

\section{Key Assumptions and Applications}

The advantage-building and the advantage-denying motive arise because of two key assumptions. First, whereas the literature on dynamic stochastic games (see, e.g., Filar and Vrieze 1997; Başar and Olsder 1999) specifies the transition probabilities $\operatorname{Pr}\left(\mathbf{e}^{\prime} \mid \mathbf{e}, \mathbf{p}\right)$ to depend directly on players' actions (in our case, firms' prices $\mathbf{p}$, we restrict the transition probabilities $\operatorname{Pr}\left(\mathbf{e}^{\prime} \mid \mathbf{e}, \mathbf{q}\right)$ to depend on $\mathbf{p}$ through the demand system $q_{1}=D_{1}(\mathbf{p}, \mathbf{e})$ and $q_{2}=D_{2}(\mathbf{p}, \mathbf{e})$.

Our second assumption is that firms set prices, not quantities. With quantity-setting, the long-run profit of incumbent firm 1 is

$$
\begin{aligned}
\Pi_{1}\left(q_{1}, q_{2}(\mathbf{e}), \mathbf{e}\right)= & \pi_{1}\left(P_{1}\left(q_{1}, q_{2}(\mathbf{e}), \mathbf{e}\right), P_{2}\left(q_{1}, q_{2}(\mathbf{e}), \mathbf{e}\right), \mathbf{e}\right)+U_{1}(\mathbf{e}) \\
& +\sum_{\mathbf{e}^{\prime} \neq \mathbf{e}}\left[U_{1}\left(\mathbf{e}^{\prime}\right)-U_{1}(\mathbf{e})\right] \operatorname{Pr}\left(\mathbf{e}^{\prime} \mid \mathbf{e}, q_{1}, q_{2}(\mathbf{e})\right),
\end{aligned}
$$

where $p_{1}=P_{1}(\mathbf{q}, \mathbf{e})$ and $p_{2}=P_{2}(\mathbf{q}, \mathbf{e})$ is the inverse demand system. The corresponding first-order condition shows that the advantage-denying motive disappears because, in contrast to the firm's price, the firm's quantity has no direct effect on its rival's quantity. 
Within the confines of these assumptions, the general model has many applications, including the models of learning-by-doing in Cabral and Riordan (1994) and Besanko et al. (2010). The models of network effects in Mitchell and Skrzypacz (2006); Chen, Doraszelski, and Harrington (2009); Dube, Hitsch, and Chintagunta (2010); and Cabral (2011), and the model of habit formation in Bergemann and Välimäki (2006) are closely related, as are the models of switching costs in Dube, Hitsch, and Rossi (2009) and Chen (2011).

More generally, in models of dynamic demand the sales in the current period determine the state of demand in the subsequent period. To the extent that firms compete for sales, a firm's price thus affects its rival's competitive position, and this gives rise to an advantage-denying motive. Demand may be dynamic in markets with durable goods (Goettler and Gordon 2011; Gowrisankaran and Rysman 2012), storable goods (Erdem, Imai, and Keane 2003; Hendel and Nevo 2006), and experience goods (Bergemann and Välimäki 1996; Ching 2010). A difference with our general model is that consumers are typically forward-looking in models of dynamic demand.

Price-setting models with costly quantity_or capacity_adjustment are another application of our general model, as are-perhaps more surprisingly-quantitysetting models with costly price adjustments (menu costs). This is because in these latter models a firm's quantity has a direct effect on its rival's price in the current period and thus competitive position in the subsequent period (see Lapham and Ware 1994 and Jun and Vives 2004 and the references therein). On the other hand, neither price-setting models with costly price adjustment nor quantity-setting models with costly quantity adjustment give rise to an advantage-denying motive.

Finally, some investment models, such as advertising models where goodwill accumulates according to a firm's "share of voice" or advertising is combative, give rise to an advantage-denying motive (see Jorgensen and Zaccour 2004 and the references therein). More generally, the advantage-denying motive is present whenever a firm's investment directly and immediately spills over into its rival's competitive position.

\section{Learning-by-Doing}

Because learning-by-doing is important in many industries where allegations of predation have surfaced in the past, we use it as an illustrative example to gain further insights into how the advantage-building and the advantage-denying motives operate and can be used to develop alternative characterizations of a firm's predatory pricing incentives. Our learning-by-doing model is closely related to Cabral and Riordan (1994) and Besanko et al. (2010) but is more general by allowing for exit and entry. Unlike Besanko et al. (2010), we abstract from organizational forgetting. ${ }^{8}$

Learning-by-Doing and Production Cost.-State $e_{n} \in\{1, \ldots, M\}$ indicates the cumulative experience or stock of know-how of incumbent firm $n$. Its marginal cost of production $c\left(e_{n}\right)$ is given by

\footnotetext{
${ }^{8}$ Empirical studies show that organizations can forget the know-how gained through learning-by-doing due to labor turnover, periods of inactivity, and failure to institutionalize tacit knowledge (Argote, Beckman, and Epple 1990; Darr, Argote, and Epple 1995; Benkard 2000; Shafer, Nembhard, and Uzumeri 2001; Thompson 2007). Besanko et al. (2010) show that organizational forgetting predisposes firms to price aggressively. Omitting organizational forgetting from the model therefore "stacks the deck" against finding predation-like behavior.
} 


$$
c\left(e_{n}\right)= \begin{cases}\kappa \rho^{\log _{2} e_{n}} & \text { if } \quad 1 \leq e_{n}<m, \\ \kappa \rho^{\log _{2} m} & \text { if } \quad m \leq e_{n} \leq M\end{cases}
$$

where $\kappa>0$ is the marginal cost for a firm without prior experience, and $\rho \in[0,1]$ is the progress ratio. Marginal cost decreases by $100(1-\rho)$ percent as the stock of know-how doubles, so a lower progress ratio implies a steeper learning curve.

An emerging firm is at the top of its learning curve in state $e_{n}=1$. As the firm makes sales, it adds to its stock of know-how and lowers its production cost in subsequent periods. Once the firm reaches state $e_{n}=m$, the learning curve "bottoms out." $A$. mature firm in state $e_{m} \geq m$ thus enjoys no further experience-based cost reductions.?

Demand.-The industry draws customers from a large pool of potential buyers. In each period, one buyer enters the market and purchases one unit of either one of the "inside goods" that are offered by the incumbent firms at prices $\mathbf{p}$ or an "outside good" at an exogenously given price $p_{0}$. The probability that incumbent firm $n$ makes the sale is given by the logit specification

$$
q_{n}=D_{n}(\mathbf{p})=\frac{\exp \left(\frac{v-p_{n}}{\sigma}\right)}{\sum_{k=0}^{2} \exp \left(\frac{v-p_{k}}{\sigma}\right)}=\frac{\exp \left(\frac{-p_{n}}{\sigma}\right)}{\sum_{k=0}^{2} \exp \left(\frac{-p_{k}}{\sigma}\right)},
$$

where $v$ is gross utility, and $\sigma>0$ is a scale parameter that governs the degree of product differentiation. As $\sigma \rightarrow 0$, goods become homogeneous.

Pricing Decision of Incumbent Firm.-The learning-by-doing model is a special case of the general model with the probability that the industry's state changes from e to $\mathbf{e}^{\prime}$ during the price-setting phase set to

$$
\operatorname{Pr}\left(\mathbf{e}^{\prime} \mid \mathbf{e}, \mathbf{q}\right)=\left\{\begin{array}{rlrl}
q_{1} & & \text { if } \mathbf{e}^{\prime}=\left(e_{1}+1, e_{2}\right), \\
q_{2} & \text { if } \mathbf{e}^{\prime}=\left(e_{1}, e_{2}+1\right), \\
1-q_{1}-q_{2} & \text { if } \mathbf{e}^{\prime}=\mathbf{e}
\end{array}\right.
$$

where $q_{n}$ is the probability that incumbent firm $n$ makes the sale as given in equation (6). The long-run profit of incumbent firm 1 in equation (4) accordingly simplifies to

$$
\begin{aligned}
\Pi_{1}\left(p_{1}, p_{2}(\mathbf{e}), \mathbf{e}\right)= & \left(p_{1}-c\left(e_{1}\right)\right) D_{1}\left(p_{1}, p_{2}(\mathbf{e})\right)+U_{1}(\mathbf{e}) \\
& +D_{1}\left(p_{1}, p_{2}(\mathbf{e})\right)\left[U_{1}\left(e_{1}+1, e_{2}\right)-U_{1}(\mathbf{e})\right] \\
& +D_{2}\left(p_{1}, p_{2}(\mathbf{e})\right)\left[U_{1}\left(e_{1}, e_{2}+1\right)-U_{1}(\mathbf{e})\right]
\end{aligned}
$$

\footnotetext{
${ }^{9}$ We obviously have to ensure $e_{n} \leq M$. To simplify the exposition we abstract from boundary issues in what follows.
} 
Because $\Pi_{1}\left(p_{1}, p_{2}(\mathbf{e}), \mathbf{e}\right)$ is strictly quasiconcave in $p_{1}\left(\right.$ given $p_{2}(\mathbf{e})$ and $\left.\mathbf{e}\right)$, the pricing decision $p_{1}(\mathbf{e})$ is uniquely determined by a first-order condition analogous to equation (5):

$$
\begin{gathered}
m r_{1}\left(p_{1}, p_{2}(\mathbf{e})\right)-c\left(e_{1}\right)+\left[U_{1}\left(e_{1}+1, e_{2}\right)-U_{1}(\mathbf{e})\right] \\
+\Upsilon\left(p_{2}(\mathbf{e})\right)\left[U_{1}(\mathbf{e})-U_{1}\left(e_{1}, e_{2}+1\right)\right]=0
\end{gathered}
$$

where $m r_{1}\left(p_{1}, p_{2}(\mathbf{e})\right)=p_{1}-\frac{\sigma}{1-D_{1}\left(p_{1}, p_{2}(\mathbf{e})\right)}$ is the marginal revenue of incumbent firm 1, or what Edlin (2012) calls inclusive price, ${ }^{10}$ and

$$
\Upsilon\left(p_{2}(\mathbf{e})\right)=\frac{\frac{\partial\left(-D_{2}\right)\left(p_{1}, p_{2}(\mathbf{e})\right)}{\partial p_{1}}}{\frac{\partial D_{1}\left(p_{1}, p_{2}(\mathbf{e})\right)}{\partial p_{1}}}=\frac{D_{2}\left(p_{1}, p_{2}(\mathbf{e})\right)}{1-D_{1}\left(p_{1}, p_{2}(\mathbf{e})\right)}=\frac{\exp \left(-\frac{p_{2}(\mathbf{e})}{\sigma}\right)}{\exp \left(-\frac{p_{0}}{\sigma}\right)+\exp \left(-\frac{p_{2}(\mathbf{e})}{\sigma}\right)}
$$

is the probability of firm 2 making a sale conditional on firm 1 not making a sale. ${ }^{11}$

Equation (8) decomposes the equilibrium pricing condition by isolating the two distinct channels through which the firm's price $p_{1}$ affects the transitions in the industry's state from $\mathbf{e}$ to $\mathbf{e}^{\prime}$ in the learning-by-doing model. First, by winning the sale in the current period, the firm moves further down its learning curve and improves its future competitive position. The reward that the firm thereby receives is the advantage-building motive $\left[U_{1}\left(e_{1}+1, e_{2}\right)-U_{1}(\mathbf{e})\right]$. Second, by winning the sale in the current period, the firm prevents its rival from moving down its learning curve and becoming a more formidable competitor in the future. The penalty that the firm thereby avoids is the advantage-denying motive $\left[U_{1}(\mathbf{e})-U_{1}\left(e_{1}, e_{2}+1\right)\right]$.

Predatory Incentives.-To detect the presence of predatory pricing, antitrust authorities ask whether a firm sacrifices current profit in exchange for the expectation of higher future profit following the exit of a rival. This sacrifice test views predatory pricing as an "investment in monopoly profit" (Bork 1978). As Edlin and Farrell (2004, p. 510) point out, "in practice sacrifice tests often use short-run data," thus equating predatory pricing with a failure to maximize short-run profit $\left(p_{1}-c\left(e_{1}\right)\right)$ $\times D_{1}\left(p_{1}, p_{2}(\mathbf{e})\right)$. This view implies that the firm's predatory pricing incentives are its dynamic incentives in their entirety:

DEFINITION 1 (Short-Run Profit): The firm's predatory pricing incentives are $\left[U_{1}\left(e_{1}+1, e_{2}\right)-U_{1}(\mathbf{e})\right]+\Upsilon\left(p_{2}(\mathbf{e})\right)\left[U_{1}(\mathbf{e})-U_{1}\left(e_{1}, e_{2}+1\right)\right]$.

Because $m r_{1}\left(p_{1}, p_{2}(\mathbf{e})\right)$ is strictly increasing in $p_{1}$, equation (8) implies that any increase in the advantage-building or the advantage-denying motive makes the firm

\footnotetext{
${ }^{10}$ See the online Appendix for details.

${ }^{11}$ To ensure that the various terms in equation (8) are expressed in monetary units we have rescaled equation (5) by$$
\frac{\partial \operatorname{Pr}\left(e_{1}+1, e_{2} \mid \mathbf{e}, D_{1}\left(p_{1}, p_{2}(\mathbf{e})\right), D_{2}\left(p_{1}, p_{2}(\mathbf{e})\right)\right)}{\partial q_{1}} \frac{\partial D_{1}\left(p_{1}, p_{2}(\mathbf{e})\right)}{\partial p_{1}}=-\frac{1}{\sigma} D_{1}\left(p_{1}, p_{2}(\mathbf{e})\right)\left(1-D_{1}\left(p_{1}, p_{2}(\mathbf{e})\right)\right) .
$$ 
more aggressive in pricing. If an improvement in the firm's competitive position is beneficial or an improvement in the rival's competition position is harmful so that $\left[U_{1}\left(e_{1}+1, e_{2}\right)-U_{1}(\mathbf{e})\right]+\Upsilon\left(p_{2}(\mathbf{e})\right)\left[U_{1}(\mathbf{e})-U_{1}\left(e_{1}, e_{2}+1\right)\right]>0$, then $m r_{1}\left(p_{1}, p_{2}(\mathbf{e})\right)<c\left(e_{1}\right)$ and the firm charges a price below the static optimum, thereby sacrificing current profit. Price may even be below marginal cost if the advantagebuilding or the advantage-denying motive is sufficiently large. ${ }^{12}$

Definition 1 is closely related to the classic Areeda and Turner (1975) test that equates predatory pricing with below-cost pricing and underpins the current Brooke Group standard for predatory pricing in the United States. Indeed, because $m r_{1}\left(p_{1}, p_{2}(\mathbf{e})\right) \rightarrow p_{1}$ as $\sigma \rightarrow 0$, in an industry with weak horizontal differentiation $\left[U_{1}\left(e_{1}+1, e_{2}\right)-U_{1}(\mathbf{e})\right]+\Upsilon\left(p_{2}(\mathbf{e})\right)\left[U_{1}(\mathbf{e})-U_{1}\left(e_{1}, e_{2}+1\right)\right]>0$ nearly implies $p_{1}<c\left(e_{1}\right)$.

Definition 1 may be too broad as it denies the efficiency gains from pricing aggressively in order to move down the learning curve by forcing a static model of profit maximization onto a dynamic world. Farrell and Katz (2005) argue forcefully that an action is predatory to the extent that it weakens the rival (see, in particular, p. 219 and p. 226). A firm should behave as if it were operating in a "dynamic competitive vacuum" in the sense that the firm takes as given the competitive position of its rival in the current period but ignores that its current price can affect the evolution of the competitive position of its rival beyond the current period. An alternative definition of predatory incentives thus centers on the advantage-denying motive:

DEFINITION 2 (Dynamic Competitive Vacuum): The firm's predatory pricing incentives are $\left[U_{1}(\mathbf{e})-U_{1}\left(e_{1}, e_{2}+1\right)\right]$.

Definition 2 disentangles predatory incentives from standard dynamic pricing incentives under learning-by-doing that can lead even a monopolist to set inclusive price below marginal cost.

In contrast to Definitions 1 and 2, the economic definitions of predation formulated in the literature focus more narrowly on the impact of a price cut on rival exit. According to Ordover and Willig (1981, pp. 9-10), “[p] redatory behavior is a response to a rival that sacrifices part of the profit that could be earned under competitive circumstances were the rival to remain viable, in order to induce exit and gain consequent additional monopoly profit." Cabral and Riordan (1997, p.160) relatedly call "an action predatory if (i) a different action would increase the probability that rivals remain viable and (ii) the different action would be more profitable under the counterfactual hypothesis that the rival's viability were unaffected."

In our dynamic stochastic game we take the "rival's viability" to refer to the probability that the rival exits the industry in the current period. Using equation (1), we decompose the advantage-building and the advantage-denying motive further

\footnotetext{
${ }^{12}$ The value function $U_{1}(\mathbf{e})$ is endogenously determined in equilibrium and, for some parameterizations, these motives fail to be positive. For example, if the industry moves into a state with aggressive price competition as the firm wins the sale, then we may have $U_{1}\left(e_{1}+1, e_{2}\right)<U_{1}(\mathbf{e})$ and we may have $U_{1}(\mathbf{e})<U_{1}\left(e_{1}, e_{2}+1\right)$ if the industry moves out of such a state as the rival wins the sale; see Section 6.1 of Besanko et al. (2010) for details.
} 
as $\left[U_{1}\left(e_{1}+1, e_{2}\right)-U_{1}(\mathbf{e})\right]=\left[\Gamma_{1}^{R E X}(\mathbf{e})+\Gamma_{1}^{-R E X}(\mathbf{e})\right]$ and $\left[U_{1}(\mathbf{e})-U_{1}\left(e_{1}, e_{2}+1\right)\right]$ $=\left[\Theta_{1}^{R E X}(\mathbf{e})+\Theta_{1}^{-R E X}(\mathbf{e})\right]$, where $\Gamma_{1}^{R E X}(\mathbf{e})$ and $\Theta_{1}^{R E X}(\mathbf{e})$ isolate the impact of a price cut on rival exit. ${ }^{13}$ In particular, the advantage-building/exit motive

$$
\Gamma_{1}^{R E X}(\mathbf{e})=\left(1-\phi_{1}(\mathbf{e})\right)\left[\phi_{2}\left(e_{1}+1, e_{2}\right)-\phi_{2}(\mathbf{e})\right] \beta\left[V_{1}\left(e_{1}+1,0\right)-V_{1}\left(e_{1}+1, e_{2}\right)\right]
$$

is the marginal benefit to the firm from increasing its rival's exit probability from $\phi_{2}(\mathbf{e})$ to $\phi_{2}\left(e_{1}+1, e_{2}\right)$. The increase in the firm's expected NPV, $\left[V_{1}\left(e_{1}+1,0\right)-\right.$ $\left.V_{1}\left(e_{1}+1, e_{2}\right)\right]$, is deflated by the probability $\left(1-\phi_{1}(\mathbf{e})\right)$ that the firm remains in the industry in the current period because otherwise the benefit is nil. The advantagedenying/exit motive

$$
\Theta_{1}^{R E X}(\mathbf{e})=\left(1-\phi_{1}(\mathbf{e})\right)\left[\phi_{2}(\mathbf{e})-\phi_{2}\left(e_{1}, e_{2}+1\right)\right] \beta\left[V_{1}\left(e_{1}, 0\right)-V_{1}(\mathbf{e})\right]
$$

is the marginal benefit to the firm from preventing its rival's exit probability from decreasing from $\phi_{2}(\mathbf{e})$ to $\phi_{2}\left(e_{1}, e_{2}+1\right)$. The increase in the firm's expected NPV, $\left[V_{1}\left(e_{1}, 0\right)-V_{1}(\mathbf{e})\right]$, is again deflated by the probability $\left(1-\phi_{1}(\mathbf{e})\right)$ that the firm remains in the industry. The remainders $\Gamma_{1}^{-R E X}(\mathbf{e})$ and $\Theta_{1}^{-R E X}(\mathbf{e})$ in the decomposed advantage-building and advantage-denying motives capture the impact of the firm's pricing decision on its competitive position within the duopoly, its rival's competitive position within the duopoly, and so on.

In the spirit of Ordover and Willig (1981) and Cabral and Riordan (1997), our final and narrowest definition of predatory incentives is:

DEFINITION 3 (Rival Exit): The firm's predatory pricing incentives are $\Gamma_{1}^{R E X}(\mathbf{e})+\Upsilon\left(p_{2}(\mathbf{e})\right) \Theta_{1}^{R E X}(\mathbf{e})$.

\section{Equilibrium and Computation}

Because the demand and cost specification is symmetric, we restrict ourselves to symmetric Markov perfect equilibria in pure strategies of our learning-by-doing model. ${ }^{14}$ Existence follows from the arguments in Doraszelski and Satterthwaite (2010). In a symmetric equilibrium, the decisions taken by firm 2 in state $\mathbf{e}=\left(e_{1}, e_{2}\right)$ are identical to the decisions taken by firm 1 in state $\left(e_{2}, e_{1}\right)$. It therefore suffices to determine the value and policy functions of firm 1.

We use the homotopy or path-following method in Besanko et al. (2010) to compute the symmetric Markov perfect equilibria of our learning-by-doing model. Although it cannot be guaranteed to find all equilibria, the advantage of this method is its ability to explore the equilibrium correspondence and search for multiple equilibria in a systematic fashion.

\footnotetext{
${ }^{13}$ This decomposition applies to an industry with two incumbent firms in state $\mathbf{e} \geq(1,1)$ and we focus on firm 1 . Because $\Gamma_{1}^{R E X}(\mathbf{e})$ and $\Theta_{1}^{R E X}(\mathbf{e})$ are typically positive, we refer to them as marginal benefits. To streamline the exposition, we further presume monotonicity of the value and policy functions. For some parameterizations these assumptions fail.

${ }^{14}$ The focus on symmetric equilibria does not imply that the industry inevitably evolves toward a symmetric structure. Depending on how successful a firm is in moving down its learning curve, it may have a cost and charge a price different from that of its rival.
} 
To explain the homotopy method, consider a single equation $H(x, \omega)=0$ in a unknown variable $x$ and a known parameter $\omega$. To the extent that there is more than one $x$ that solves $H(x, \omega)=0$ given $\omega$, the mapping $H^{-1}(\omega)=\{x \mid H(x, \omega)=0\}$ from parameters into variables is a correspondence. We think of $H(x, \omega)=0$ as the equilibrium condition and of $H^{-1}(\omega)=\{x \mid H(x, \omega)=0\}$ as the equilibrium correspondence. This correspondence takes the form of one or more "paths" through $(x, \omega)$-space, and the homotopy method seeks to trace out these paths.

It does so by introducing an auxiliary variable $s$ to define a parametric curve $(x(s), \omega(s)) \in H^{-1}(\omega)=\{x \mid H(x, \omega)=0\}$. Differentiating $H(x(s), \omega(s))=0$ with respect to $s$ yields $\frac{\partial H(x(s), \omega(s))}{\partial x} x^{\prime}(s)+\frac{\partial H(x(s), \omega(s))}{\partial x} \omega^{\prime}(s)=0$. Starting from a point $(x(s), \omega(s))$ on the path, this differential equation prescribes how $x$ and $\omega$ must change to obtain another point on the path. The homotopy method reduces the task of solving the equation $H(x, \omega)=0$ to the task of solving this differential equation. This requires an initial condition in the form of a known point on the path. If we do not have an initial condition for a path in $H^{-1}(\omega)=\{(x, \omega) \mid H(x, \omega)=0\}$, then we may not be able to trace it out and will therefore miss some solutions to $H(x, \omega)=0$.

Computing the equilibria of our learning-by-doing model mirrors the above example except that it involves many equilibrium conditions $\mathbf{H}(\mathbf{x}, \boldsymbol{\omega})=0$ (Bellman equations and optimality conditions), many variables $\mathbf{x}=\left(\mathbf{V}_{1}, \mathbf{U}_{1}, \mathbf{p}_{1}, \phi_{1}\right)$ (values and policies), and many parameters $\omega=(\rho, \sigma, \bar{X}, \ldots) \cdot \cdot^{15}$ To explore the equilibrium correspondence $\mathbf{H}^{-1}(\boldsymbol{\omega})=\{\mathbf{x} \mid \mathbf{H}(\mathbf{x}, \boldsymbol{\omega})=0\}$, we compute slices of it by varying a parameter of the model such as the progress ratio $\rho$ while holding the remaining parameters fixed. We denote a slice of the equilibrium correspondence along $\rho$ by $\mathbf{H}^{-1}(\rho)$ in what follows.

To try and identify as many equilibria as possible, we proceed in an intuitively appealing but potentially fallible way. Just as we can vary the progress ratio $\rho$ while holding the remaining parameters fixed, we can vary the degree of product differentiation $\sigma$ while holding the remaining parameters fixed. We "crisscross" the parameter space in an orderly fashion by using the equilibria on the $\rho$-slices as initial conditions to generate $\sigma$-slices. A $\sigma$-slice must either intersect with all $\rho$-slices or lead us to an additional equilibrium that, in turn, gives us an initial condition to generate an additional $\rho$-slice. We continue this process until all $\sigma$ - and $\rho$-slices "match up." We denote the resulting two-dimensional slice through the equilibrium correspondence by $\mathbf{H}^{-1}(\rho, \sigma)$. We employ the same procedure to obtain two-dimensional slices $\mathbf{H}^{-1}(\rho, \bar{X})$ and $\mathbf{H}^{-1}(\sigma, \bar{X})$. This gives us three intersecting two-dimensional slices that we use to explore the economic significance of predatory incentives.

To compute a slice through the equilibrium correspondence along one or more parameters of interest, we hold the remaining parameters fixed at the values in Table 1. While this baseline parameterization is not intended to be representative of any particular industry, it is neither entirely unrepresentative nor extreme.

\footnotetext{
${ }^{15}$ See Besanko et al. (2010) and Borkovsky, Doraszelski, and Kryukov (2010, 2012) for details. Our codes are available upon request.
} 
Table 1 -Baseline Parameterization

\begin{tabular}{lc}
\hline \hline Parameter & Value \\
\hline Maximum stock of know-how $M$ & 30 \\
Price of outside good $p_{0}$ & 10 \\
Gross utility $v$ & 10 \\
Product differentiation $\sigma$ & 1 \\
Cost at top of learning curve $\kappa$ & 10 \\
Bottom of learning curve $m$ & 15 \\
Progress ratio $\rho$ & 0.75 \\
Scrap value $\bar{X}, \Delta_{X}$ & $1.5,1.5$ \\
Setup cost $\bar{S}, \Delta_{S}$ & $4.5,1.5$ \\
Discount factor $\beta$ & 0.9524 \\
\hline
\end{tabular}

\section{Predation-Like Behavior}

To illustrate the types of behavior that can emerge in our learning-by-doing model, we examine the equilibria that arise for the baseline parameterization in Table 1. For two of these three equilibria Figure 1 shows the pricing decision of firm 1, the nonoperating probability of firm 2 , and the time path of the probability distribution over industry structures (empty, monopoly, and duopoly). ${ }^{16}$

The upper panels of Figure 1 exemplify what we call an aggressive equilibrium. The pricing decision in the upper left panel exhibits a deep well in state $(1,1)$ with $p 1(1,1)=-34.78$. A well is a preemption battle where firms vie to be the first to move down from the top of their learning curves. The pricing decision further exhibits a deep trench along the $e 1$-axis with $p 1(e 1,1)$ ranging from 0.08 to 1.24 for $e$ $1 \in\{2, \ldots, 30\} .{ }^{17}$ A trench is a price war that the leader (firm 1) wages against the follower (firm 2). One can think of a trench as an endogenously arising mobility barrier in the sense of Caves and Porter (1977). In the trench the follower exits the industry with a positive probability of $\phi 2(e 1,1)=0.22$ for $e 1 \in\{2, \ldots, 30\}$ as the upper middle panel shows. The follower remains in this exit zone as long as it does not win a sale. Once the follower exits, the leader raises its price and the industry becomes an entrenched monopoly. ${ }^{18}$ This sequence of events resembles conventional notions of predatory pricing. The industry may also evolve into a mature duopoly if the follower manages to crash through the mobility barrier by winning a sale but, as the upper right panel of Figure 1 shows, this is far less likely than an entrenched monopoly.

The lower panels of Figure 1 are typical for an accommodative equilibrium. There is a shallow well in state $(1,1)$ with $p_{1}(1,1)=5.05$ as the lower left panel shows. Without mobility barriers in the form of trenches, however, any competitive advantage is temporary and the industry evolves into a mature duopoly as the lower right panel shows.

To further illustrate how industry dynamics differ between the aggressive and accommodative equilibria, we use the policy functions $\mathbf{p}_{1}$ and $\phi_{1}$ for a particular equilibrium to construct the matrix of state-to-state transition probabilities that

\footnotetext{
${ }^{16}$ The third equilibrium is essentially intermediate between the two shown in Figure 1.

${ }^{17}$ Because prices are strategic complements, there is also a shallow trench along the $e_{2}$-axis with $p_{1}\left(1, e_{2}\right)$ ranging from 3.63 to 4.90 for $e_{2} \in\{2, \ldots, 30\}$.

${ }^{18}$ While our model allows for re-entry, whether it actually occurs depends on how a potential entrant assesses its prospects in the industry. In this particular equilibrium, $\phi_{2}\left(e_{1}, 0\right)=1.00$ for $e_{1} \in\{2, \ldots, 30\}$, so that the potential entrant does not enter if the incumbent firm has moved down from the top of its learning curve.
} 

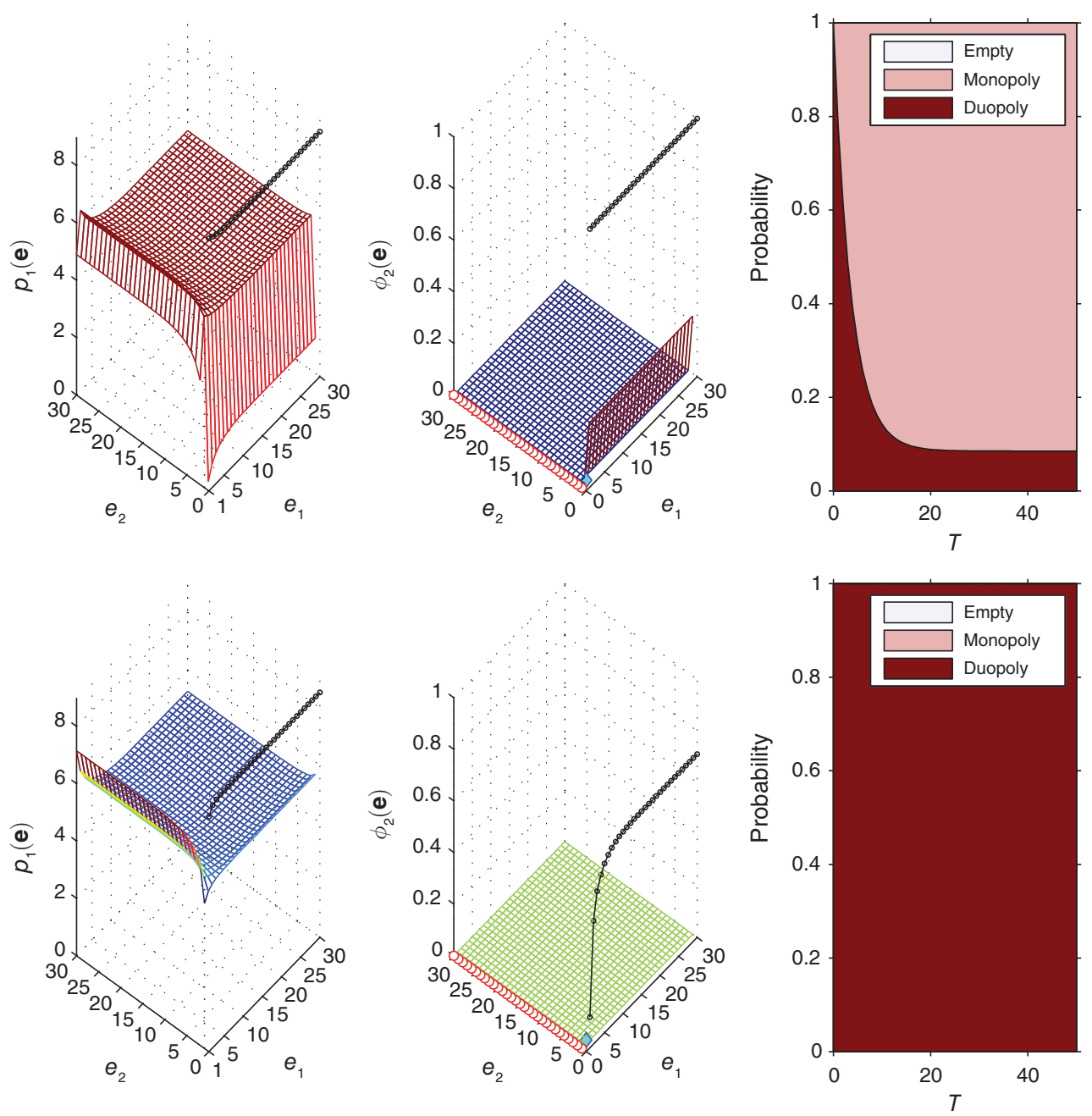

Figure 1. Aggressive And Accomodative Equilibria

Notes: Pricing decision of firm 1 (left panels), nonoperating probability of firm 2 (middle panels), and time path of probability distribution over industry structures, starting from $\mathbf{e}=(1,1)$ at $T=0$ (right panels). Aggressive (upper panels) and accommodative (lower panels) equilibria.

characterizes the Markov process of industry dynamics. From this, we compute the transient distribution over states in period $T, \boldsymbol{\mu}^{T}$, starting from state $(1,1)$ in period 0. Depending on $T$, the transient distributions can capture short-run or long-run (steady-state) dynamics. We think of period 1,000 as the long run and, with a slight abuse of notation, denote $\boldsymbol{\mu}^{1,000}$ by $\boldsymbol{\mu}^{\infty}$. We use the transient distribution in period 1,000 rather than the limiting (or ergodic) distribution to capture long-run dynamics because the Markov process implied by the equilibrium under consideration may have multiple closed communicating classes. ${ }^{19}$

\footnotetext{
${ }^{19}$ The vast majority of equilibria that we have computed has either one or two closed communicating classes. If there is one, it typically is a mature duopoly; if there are two, they are a mature monopoly and a mature duopoly. The multiple closed communicating classes that arise for a particular equilibrium are conceptually different from
} 
Table 2-Most Likely Industry Structure, Pricing Decisions, And Nonoperating Probabilities

\begin{tabular}{|c|c|c|c|c|c|c|c|c|c|c|}
\hline \multirow[b]{2}{*}{$T$} & \multicolumn{5}{|c|}{ Aggressive equilibrium } & \multicolumn{5}{|c|}{ Accommodative equilibrium } \\
\hline & e & $p_{1}(\mathbf{e})$ & $p_{2}(\mathbf{e})$ & $\phi_{1}(\mathbf{e})$ & $\phi_{2}(\mathbf{e})$ & e & $p_{1}(\mathbf{e})$ & $p_{2}(\mathbf{e})$ & $\phi_{1}(\mathbf{e})$ & $\phi_{2}(\mathbf{e})$ \\
\hline 0 & $(1,1)$ & -34.78 & -34.78 & 0.00 & 0.00 & $(1,1)$ & 5.05 & 5.05 & 0.00 & 0.00 \\
\hline 1 & $(2,1)$ & 0.08 & 3.63 & 0.00 & 0.22 & $(2,1)$ & 5.34 & 6.29 & 0.00 & 0.00 \\
\hline 2 & $(3,1)$ & 0.56 & 4.15 & 0.00 & 0.22 & $(3,1)$ & 5.45 & 6.65 & 0.00 & 0.00 \\
\hline 3 & $(4,1)$ & 0.80 & 4.41 & 0.00 & 0.22 & $(4,1)$ & 5.51 & 6.82 & 0.00 & 0.00 \\
\hline 4 & $(5,0)$ & 8.62 & - & 0.00 & 1.00 & $(5,1)$ & 5.54 & 6.93 & 0.00 & 0.00 \\
\hline 5 & $(6,0)$ & 8.60 & - & 0.00 & 1.00 & $(6,1)$ & 5.56 & 7.00 & 0.00 & 0.00 \\
\hline 6 & $(7,0)$ & 8.59 & - & 0.00 & 1.00 & $(4,4)$ & 5.65 & 5.65 & 0.00 & 0.00 \\
\hline 7 & $(8,0)$ & 8.58 & - & 0.00 & 1.00 & $(5,4)$ & 5.56 & 5.68 & 0.00 & 0.00 \\
\hline 8 & $(9,0)$ & 8.57 & - & 0.00 & 1.00 & $(5,5)$ & 5.57 & 5.57 & 0.00 & 0.00 \\
\hline 9 & $(9,0)$ & 8.57 & - & 0.00 & 1.00 & $(6,5)$ & 5.50 & 5.59 & 0.00 & 0.00 \\
\hline 10 & $(10,0)$ & 8.56 & - & 0.00 & 1.00 & $(6,6)$ & 5.51 & 5.51 & 0.00 & 0.00 \\
\hline 20 & $(18,0)$ & 8.54 & - & 0.00 & 1.00 & $(11,11)$ & 5.29 & 5.29 & 0.00 & 0.00 \\
\hline 50 & $(30,0)$ & 8.54 & - & 0.00 & 1.00 & $(26,26)$ & 5.24 & 5.24 & 0.00 & 0.00 \\
\hline$\infty$ & $(30,0)$ & 8.54 & - & 0.00 & 1.00 & $(30,30)$ & 5.24 & 5.24 & 0.00 & 0.00 \\
\hline
\end{tabular}

Note: Restricted to mode with $e_{1} \geq e_{2}$.

For the aggressive equilibrium, the left panel of Table 2 reports the most likely industry structure at various times $T$ as given by the mode of the transient distribution $\mu^{T}$ along with firms' pricing decisions and non-operating probabilities. After the industry has emerged from the preemption battle in period 1, the leader (firm 1) prices aggressively in order to keep the follower (firm 2) in the exit zone. By period 4 the follower has most likely exited the industry and the leader raises its price. From thereon, the industry remains an entrenched monopoly. For the accommodative equilibrium, after the industry emerges from the preemption battle in period 1, the leader enjoys a competitive advantage over the follower. As can be seen in the right panel, this advantage is temporary: after period 5 the most likely industry structure is symmetric (or almost symmetric). The industry ultimately becomes a mature duopoly.

\section{A. Industry Structure, Conduct, and Performance}

To succinctly describe an equilibrium we use six metrics of industry structure, conduct, and performance (SCP).

Structure: Expected long-run Herfindahl index:

$$
H H I^{\infty}=\sum_{\mathbf{e} \geq(0,0)} \frac{\mu^{\infty}(\mathbf{e})}{1-\mu^{\infty}(0,0)} H H I(\mathbf{e}),
$$

where the Herfindahl index in state $\mathbf{e}$ is

$$
H H I(\mathbf{e})=\left[\sum_{n=1}^{2} \frac{D_{n}\left(p_{1}(\mathbf{e}), p_{2}(\mathbf{e})\right)}{D_{1}\left(p_{1}(\mathbf{e}), p_{2}(\mathbf{e})\right)+D_{2}\left(p_{1}(\mathbf{e}), p_{2}(\mathbf{e})\right)}\right]^{2} .
$$

multiple equilibria. A closed communicating class is a set of states from which there is no escape once the industry has entered it. In the aggressive equilibrium, once the industry evolves into a mature monopoly, respectively, duopoly it remains a mature monopoly, respectively, duopoly forever. The transient distribution in period 1,000 accounts for the probability of reaching any one of these closed communicating classes, starting from state $(1,1)$ in period 0 . 
If $H H I^{\infty}>0.5$, then an asymmetric industry structure arises and persists.

Conduct: Expected long-run average price:

$$
\bar{p}^{\infty}=\sum_{\mathbf{e} \geq(0,0)} \frac{\mu^{\infty}(\mathbf{e})}{1-\mu^{\infty}(0,0)} \bar{p}(\mathbf{e}),
$$

where the (share-weighted) average price in state $\mathbf{e}$ is

$$
\bar{p}(\mathbf{e})=\sum_{n=1}^{2} \frac{D_{n}\left(p_{1}(\mathbf{e}), p_{2}(\mathbf{e})\right)}{D_{1}\left(p_{1}(\mathbf{e}), p_{2}(\mathbf{e})\right)+D_{2}\left(p_{1}(\mathbf{e}), p_{2}(\mathbf{e})\right)} p_{n}(\mathbf{e}) .
$$

Performance: Expected long-run consumer surplus:

$$
C S^{\infty}=\sum_{\mathbf{e}} \mu^{\infty}(\mathbf{e}) C S(\mathbf{e}),
$$

where $C S(\mathbf{e})$ is consumer surplus in state $\mathbf{e}$.

Expected long-run total surplus:

$$
T S^{\infty}=\sum_{\mathbf{e}} \mu^{\infty}(\mathbf{e})\left\{C S(\mathbf{e})+\sum_{n=1}^{2} P S_{n}(\mathbf{e})\right\},
$$

where $P S_{n}(\mathbf{e})$ is the producer surplus of firm $n$ in state $\mathbf{e} .^{20}$

Expected discounted consumer surplus:

$$
C S^{N P V}=\sum_{T=0}^{\infty} \beta^{T} \sum_{\mathbf{e}} \mu^{T}(\mathbf{e}) C S(\mathbf{e}) .
$$

Expected discounted total surplus:

$$
T S^{N P V}=\sum_{T=0}^{\infty} \beta^{T} \sum_{\mathbf{e}} \mu^{T}(\mathbf{e})\left\{C S(\mathbf{e})+\sum_{n=1}^{2} P S_{n}(\mathbf{e})\right\} .
$$

By focusing on the states that arise in the long run (as given by $\mu^{\infty}$ ), $C S^{\infty}$ and $T S^{\infty}$ summarize the long-run implications of equilibrium behavior for industry performance. In contrast, $C S^{N P V}$ and $T S^{N P V}$ summarize the short-run and the long-run implications that arise along entire time paths of states (as given by $\boldsymbol{\mu}^{0}, \boldsymbol{\mu}^{1}, \ldots$ ). Hence, $C S^{N P V}$ and $T S^{N P V}$ reflect any short-run competition for the market as well as any long-run competition in the market.

Table 3 illustrates the SCP metrics for the equilibria at the beginning of Section III. The industry is substantially more likely to be monopolized under the aggressive equilibrium than under the accommodative equilibrium. Prices are higher, and consumer and total surplus are lower, under the aggressive equilibrium than under the

\footnotetext{
${ }^{20}$ See the online Appendix for expressions for $C S(\mathbf{e})$ and $P S_{n}(\mathbf{e})$.
} 
Table 3-Industry Structure, Conduct, and Performance. Aggressive and AcCommodative EQuiLibria

\begin{tabular}{lcc}
\hline \hline & Aggressive equilibrium & Accommodative equilibrium \\
\hline$H H I^{\infty}$ & 0.96 & 0.50 \\
$\bar{p}^{\infty}$ & 8.26 & 5.24 \\
$C S^{\infty}$ & 1.99 & 5.46 \\
$T S^{\infty}$ & 6.09 & 7.44 \\
$C S^{N P V}$ & 104.18 & 109.07 \\
$T S^{N P V}$ & 110.33 & 120.14 \\
\hline
\end{tabular}

accommodative equilibrium. The difference between the equilibria is smaller for $C S^{N P V}$ than for $C S^{\infty}$ because the former metric accounts for the competition for the market in the short run that manifests itself in the deep well and trench of the aggressive equilibrium. The competition for the market in the short run mitigates to some extent the lack of competition in the market in the long run.

\section{B. Equilibrium Correspondence}

For clarity, we use our metric of industry structure to depict one-dimensional slices through the equilibrium correspondence. See the online Appendix for additional figures and tables.

Progress Ratio.-Panel A of Figure 2 illustrates the equilibrium correspondence by plotting $H H I^{\infty}$ against $\rho$. If $\rho=1$ there is no learning-by-doing, while if $\rho=0$ the learning economies become infinitely strong in the sense that the marginal cost of production jumps from $\kappa$ for the first unit to 0 for any further unit. The progress ratio $\rho$ therefore determines the possible extent of efficiency gains from pricing aggressively in order to move down the learning curve.

There are multiple equilibria for $\rho$ from 0 to $0.80 . \mathbf{H}^{-1}(\rho)$ involves a main path (labeled $M P$ ) with one equilibrium for $\rho$ from 0 to 1 , a semi-loop $(S L)$ with two equilibria for $\rho$ from 0 to 0.80 , and three loops $\left(L_{1}, L_{2}\right.$, and $\left.L_{3}\right)$ each with two equilibria for $\rho$ from 0.25 to $0.70,0.35$ to 0.65 , and 0.36 to 0.53 , respectively.

The equilibria on $M P$ are accommodative. The industry evolves into a mature duopoly with $H H I^{\infty}=0.5$ as in the accommodative equilibrium at the beginning of Section III. The equilibria on the lower fold of $S L$ similarly involve an almost symmetric industry structure. The equilibria on the upper fold of $S L$ as well as those on $L_{1}, L_{2}$, and $L_{3}$ are aggressive. As in the aggressive equilibrium at the beginning of Section III, the industry evolves into an entrenched monopoly with $H H I^{\infty} \approx 1.0 .{ }^{21}$

Product Differentiation.-Panel B of Figure 2 plots $H H I^{\infty}$ against $\sigma$. The degree of product differentiation $\sigma$ influences how desirable it is for a firm to induce its rival to exit the industry: As $\sigma \rightarrow 0$ the goods become homogenous, competition

\footnotetext{
${ }^{21}$ Aggressive equilibria can arise even if there is practically no learning-by-doing, e.g., if $\rho=0.99$ and $\sigma=0.10$ or $\rho=0.98$ and $\sigma=0.30$. See the online Appendix for details.
} 
Panel A

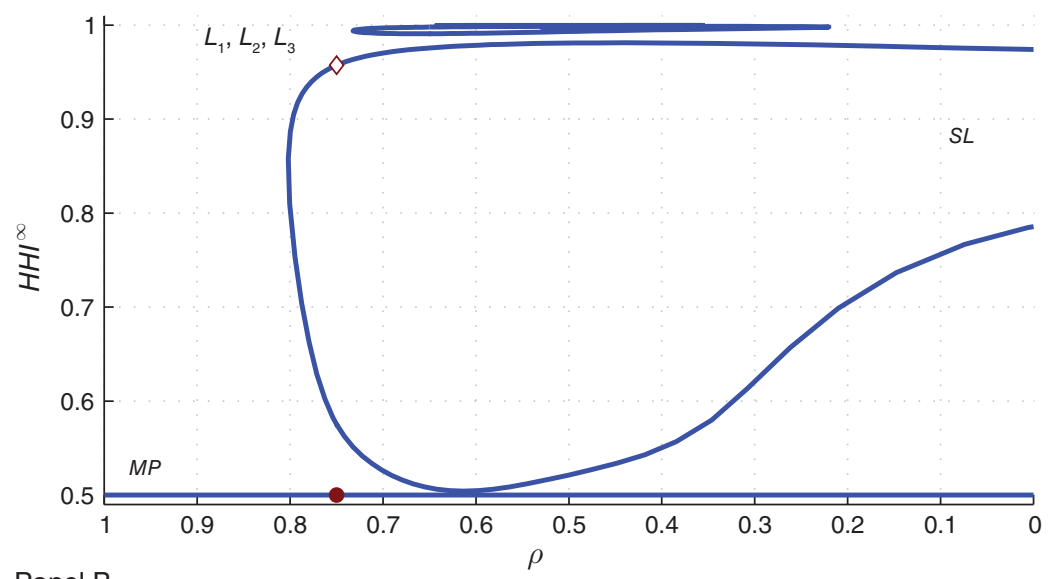

Panel B

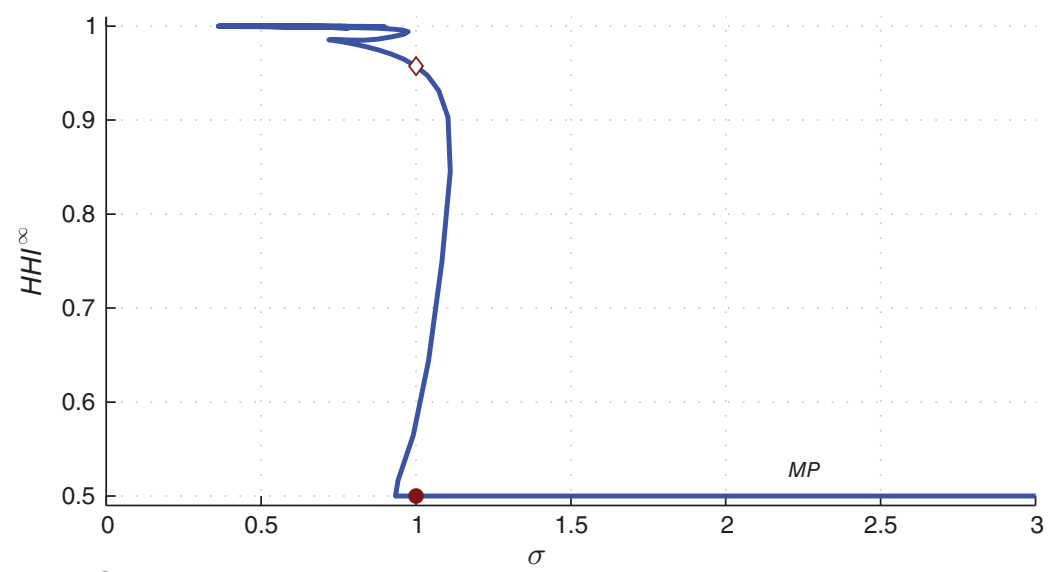

Panel C

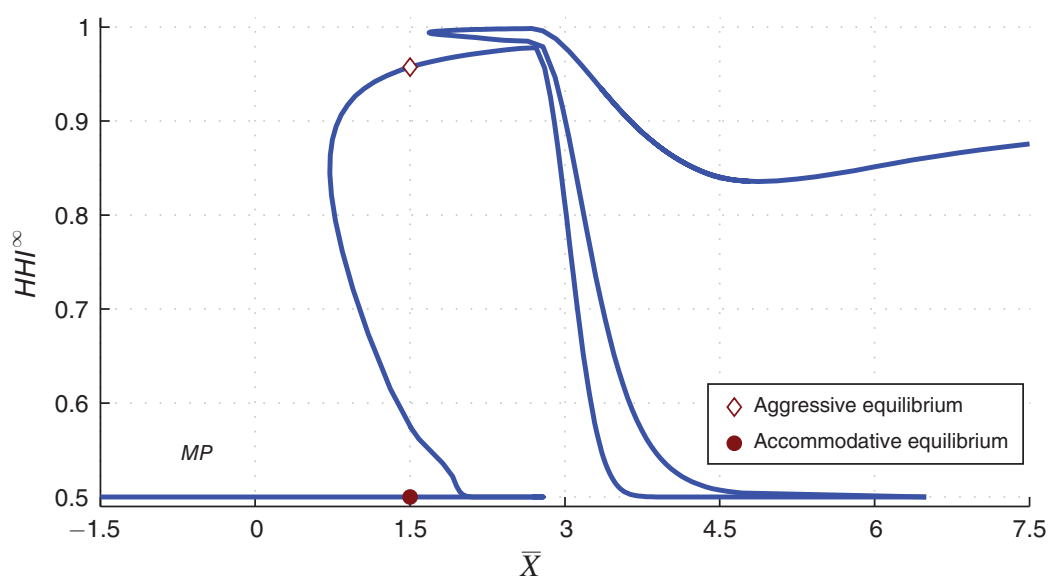

Figure 2. EQuilibrium CoRresPondence

Note: Expected long-run Herfindahl index: slice along $\rho \in[0,1]$ (panel A), $\sigma \in[0,3]$ (panel B), and $\bar{X} \in[-1.75,7.5]$ (panel C). 
intensifies, and profits fall. Product differentiation is already very weak for $\sigma=0.3$ and moderately strong for $\sigma=3 .^{22}$

There are multiple equilibria for $\sigma$ below 1.10. While $\mathbf{H}^{-1}(\sigma)$ involves just a main path (labeled $M P$ ), multiple equilibria arise as this path bends back on itself. The equilibria on the lower fold of $M P$ are accommodative and the industry evolves into a mature duopoly. The equilibria on the upper fold of $M P$ are aggressive and the industry evolves into an entrenched monopoly.

Scrap Value.-Panel C of Figure 2 plots $H H I^{\infty}$ against the $\bar{X}$. The expected scrap value $\bar{X}$ determines how easy it is for a firm to induce its rival to exit the industry. Because a firm can always guarantee itself a nonnegative short-run profit, exit is impossible if $\bar{X}+\Delta_{X}<0 \Leftrightarrow \bar{X}<-1.5$. As $\bar{X} \rightarrow \infty$, exit becomes inevitable. At the same time, however, exit is immediately followed by entry. In particular, if $\bar{X}-\Delta_{X}>\bar{S}+\Delta_{S} \Leftrightarrow \bar{X}>7.5$, then a potential entrant has an incentive to incur the setup cost for the exclusive purpose of receiving the scrap value. ${ }^{23}$

There are multiple equilibria for $\bar{X}$ from 0.7 to $6.5 . \mathbf{H}^{-1}(\bar{X})$ involves a main path (labeled $M P$ ) that bends back on itself. The equilibria on the lower fold of $M P$ are accommodative and the industry evolves into a mature duopoly. The equilibria on the upper fold of $M P$ are aggressive and the industry evolves into an entrenched monopoly.

Overall, many equilibria are aggressive. In these equilibria, predation-like behavior arises. Generally speaking, aggressive equilibria tend to arise with a lower progress ratio $\rho$, a lower degree of product differentiation $\sigma$, and a higher expected scrap value $\bar{X} \cdot{ }^{24}$ Aggressive equilibria often coexist with accommodative equilibria, and multiplicity of equilibria is the norm rather than the exception. The sheer number of equilibria can be staggering; we have found up to 221 equilibria for some parameterizations. ${ }^{25}$ However, the number of equilibria varies widely across parameterizations; see the online Appendix for details.

\section{Economic Significance of Predatory Incentives}

Are predatory incentives economically significant in their impact on the evolution of the industry? To address this question, we imagine an omniscient regulator that can force firms to ignore the predatory incentives in setting their prices. To do so, the regulator imposes a constraint $\Xi_{1}\left(p_{1}, p_{2}(\mathbf{e}), \mathbf{e}\right)=0$ on the maximization problem on the right-hand side of the Bellman equation (3) that a firm solves in the price-setting phase. The constraint "switches off" the predatory incentives

\footnotetext{
${ }^{22}$ The homotopy algorithm sometimes fails for $\sigma$ below 0.3 . For $\sigma=0.3$ in an emerging duopoly the own- and cross-price elasticities of demand are -28.17 and 6.38, respectively, at static Nash equilibrium prices and -6.42 and 6.42 in a mature duopoly. For $\sigma=3$ the own- and cross-price elasticities are -3.72 and 0.84 , respectively, in an emerging duopoly, and -1.66 and 1.07 in a mature duopoly.

${ }^{23}$ Our model cannot capture perfect contestability, which requires $\Delta_{X}=\Delta_{S}=0$ in addition to $\bar{X}=\bar{S}$.

${ }^{24}$ With more than two firms, the incentive to price aggressively may be muted because it is costly and eliminating a competitor from the industry benefits all surviving firms. A firm may thus prefer another firm to price aggressively rather than to do so itself. This externality is well-understood in merger analysis (Stigler 1950). Because the benefits of focusing on two firms are substantial, both in terms of computational burden and in terms of presenting the results, we leave it to future work to extend the analysis to more firms.

${ }^{25}$ Many of these equilibria differ in the number, location, or depth of the trenches and corresponding exit zones but induce broadly similar industry dynamics.
} 
according to a particular definition. For example, according to Definition 2 the predatory incentives are $\left[U_{1}(\mathbf{e})-U_{1}\left(e_{1}, e_{2}+1\right)\right]$, so the constraint is $\Xi_{1}\left(p_{1}, p_{2}(\mathbf{e}), \mathbf{e}\right)$ $=m r_{1}\left(p_{1}, p_{2}(\mathbf{e})\right)-c\left(e_{1}\right)+\left[U_{1}\left(e_{1}+1, e_{2}\right)-U_{1}(\mathbf{e})\right]=0$. We use the homotopy method to compute the symmetric Markov perfect equilibria of the counterfactual game with the conduct restriction in place. As described in Section II, we compute three intersecting two-dimensional slices along $(\rho, \sigma),(\rho, \bar{X})$, and $(\sigma, \bar{X})$.

\section{A. Counterfactual and Equilibrium Correspondences}

Our computations show that for all parameterizations the counterfactual is unique for Definition 1 but not necessarily for Definitions 2 and 3, where we have found up to 3 and 103, respectively, counterfactuals for some parameterizations. Even for Definition 3, however, there tend to be fewer counterfactuals than equilibria for a given parameterization.

Figure 3 illustrates the counterfactual correspondences for Definitions $1-3$ by plotting $H H I^{\infty}$ against $\rho$. For clarity, we again focus on one-dimensional slices. We superimpose the equilibrium correspondence $\mathbf{H}^{-1}(\rho)$ from Figure 2.

For Definitions 1 and 2, the counterfactual correspondence consists of a main path. In the counterfactuals the industry evolves into a mature duopoly with $H H^{\infty}=0.5$. Further inspection shows that the counterfactuals are accommodative. ${ }^{26}$ While the accommodative equilibria on $M P$ and the lower fold of $S L$ have a counterfactual "nearby," the aggressive equilibria on the upper fold of $S L$ as well as those on $L_{1}, L_{2}$, and $L_{3}$ do not. For example, for the baseline parameterization, the accommodative but not the aggressive equilibrium seems to have a counterfactual counterpart.

By contrast, the counterfactual correspondence for Definition 3 resembles the equilibrium correspondence and consists of a main path, a semi-loop, and one loop. The counterfactuals span the same range of industry structures as the equilibria. Most, but not all, equilibria have a counterfactual "nearby."

\section{B. Eliminated and Surviving Equilibria}

By illustrating that there are equilibria that do not have a counterfactual counterpart, Figure 3 suggests that some equilibria hinge on the predatory incentives. Put differently, forcing firms to ignore the predatory incentives in setting their prices eliminates some equilibria whereas other equilibria survive. To formalize this intuition, we use the homotopy method to link the counterfactual and equilibrium correspondences. Instead of abruptly "switching off" the predatory incentives, we gradually drive them to zero. For Definition 2, for example, we put a weight $\lambda$ on $\left[U_{1}(\mathbf{e})-U_{1}\left(e_{1}, e_{2}+1\right)\right]$ in forming the constraint $\Xi_{1}\left(p_{1}, p_{2}(\mathbf{e}), \mathbf{e}\right)=0$, and we then allow the homotopy method to vary $\lambda$ (along with the vector of values and policies $\left.\mathbf{x}=\left(\mathbf{V}_{1}, \mathbf{U}_{1}, \mathbf{p}_{1}, \phi_{1}\right)\right)$. At $\lambda=1$ we have an equilibrium and at $\lambda=0$ we have a counterfactual. We say that an equilibrium survives if, starting from $\lambda=1$, the homotopy reaches the counterfactual correspondence. A surviving equilibrium smoothly deforms into a symmetric Markov perfect equilibrium of the counterfactual game

\footnotetext{
${ }^{26}$ This is not true elsewhere in parameter space, e.g., at lower levels of product differentiation than the baseline parameterization.
} 
Panel A

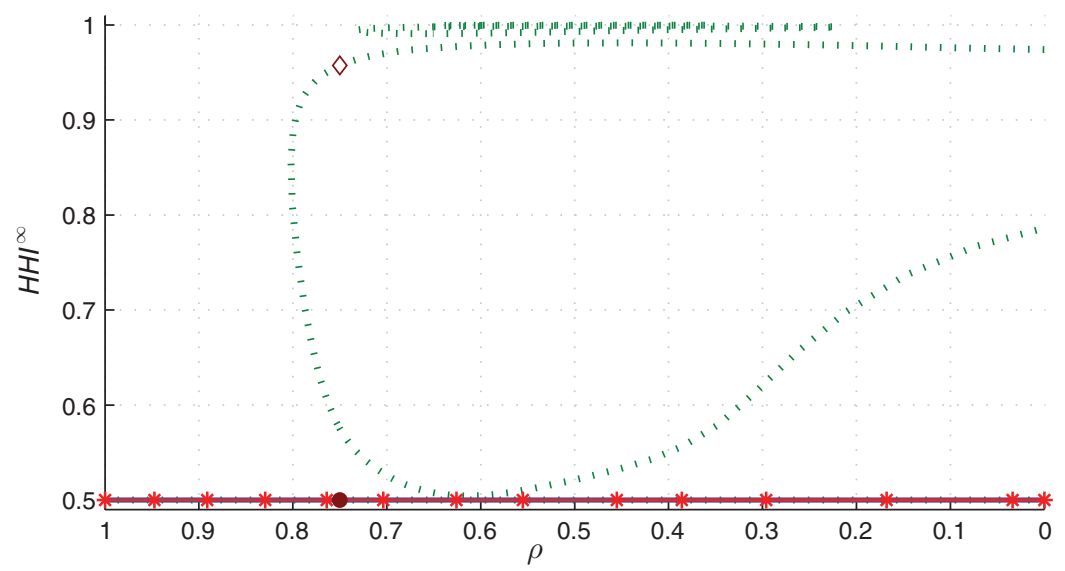

Panel B

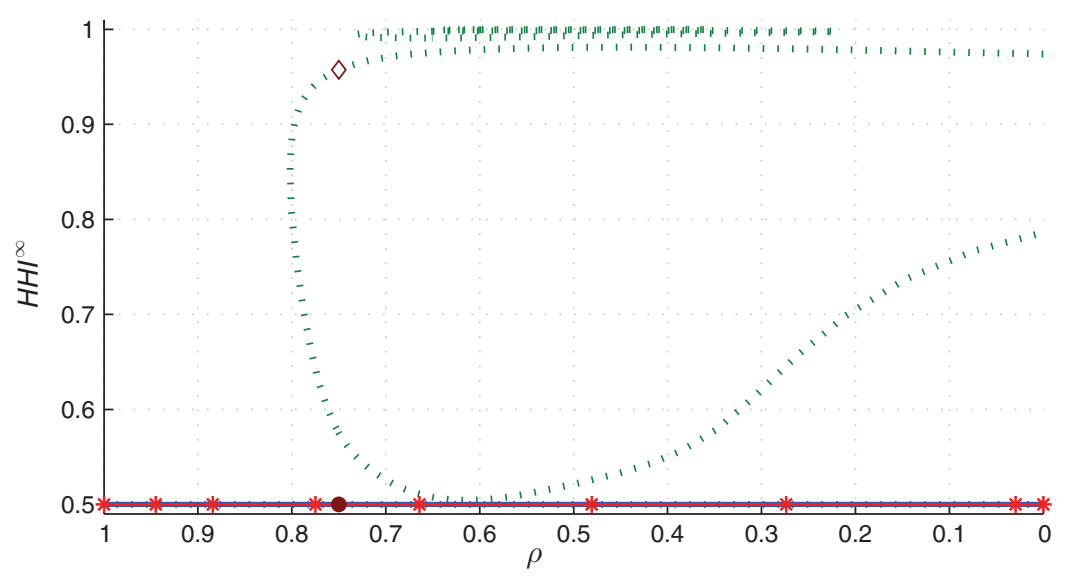

Panel C

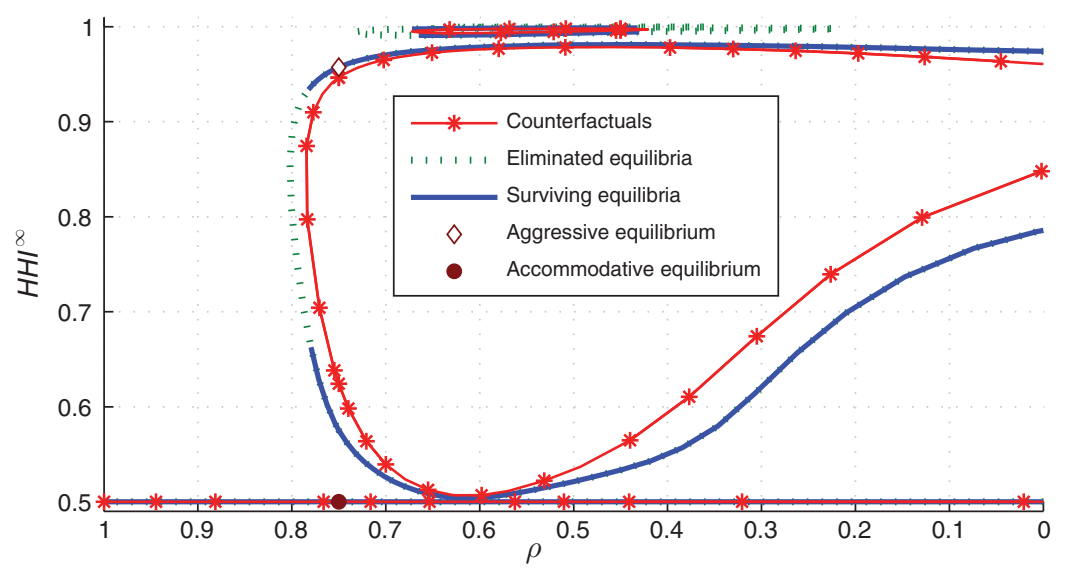

Figure 3. Counterfactual and EQuilibrium Correspondences

Notes: Expected long-run Herfindahl index for Definitions 1-3 (panels A, B, and C) along with eliminated (dashed line) and surviving (solid line) equilibria. Slice along $\rho \in[0,1]$. 
by gradually tightening the conduct restriction. We say that an equilibrium is eliminated if the homotopy algorithm returns to the equilibrium correspondence. ${ }^{27}$

Figure 3 distinguishes between eliminated and surviving equilibria for Definitions 1-3. Definitions 1 and 2 eliminate the aggressive equilibria that are associated with higher expected long-run Herfindahl indices whereas the accommodative equilibria that are associated with lower expected long-run Herfindahl indices survive. By contrast, some of the more aggressive equilibria survive Definition 3 , along with all the more accommodative ones. Nevertheless, Definition 3 eliminates at least some of the aggressive equilibria.

To illustrate, for the baseline parameterization with $\rho=0.75$, all three equilibria (including the aggressive and accommodative equilibria at the beginning of Section III) survive Definition 3. For $\rho=0.8$, one of the three equilibria survives; the two most aggressive equilibria with $H H^{\infty}{ }^{\infty}=0.80$ and $H H I^{\infty}=0.89$ are eliminated. For $\rho=0.7$ three of the five equilibria survive; again the two most aggressive equilibria with $H H I^{\infty}=0.99$ and $H H I^{\infty}=1.00$ are eliminated.

These patterns are general. The first row of Table 4 shows the percentage of eliminated and surviving equilibria for the two-dimensional slices along $(\rho, \sigma),(\rho, \bar{X})$, and $(\sigma, \bar{X})$ through the equilibrium correspondence. We restrict attention to parameterizations with multiple equilibria because if an equilibrium is unique, then (under some regularity conditions) it necessarily survives. In line with Figure 3, the broader Definitions 1 and 2 eliminate many more equilibria than the narrower Definition 3.

The remaining rows of Table 4 show how industry structure, conduct, and performance differ between eliminated and surviving equilibria. We report averages and standard deviations of the SCP metrics that equally weigh parameterizations in order to compensate for the different number of equilibria at different parameterizations. In the long run, the eliminated equilibria have, on average, higher concentration and prices and lower consumer and total surplus than the surviving equilibria. The eliminated equilibria thus tend to be "worse" in the long run than the surviving equilibria.

The eliminated equilibria also have, on average, lower discounted consumer and total surplus than the surviving equilibria. These differences are, however, much smaller than the differences in the corresponding long-run metrics. This is because, although they have less competition in the market in the long run, the eliminated equilibria tend to have more competition for the market in the short run than the surviving equilibria. As consumers benefit — at least in the short run-from the aggressive pricing in the wells and trenches that are part and parcel of competition for the market, the difference between eliminated and surviving equilibria is much smaller for $C S^{N P V}$ than for $C S^{\infty}$.

In sum, forcing firms to ignore the predatory incentives in setting their prices eliminates equilibria involving high concentration and prices and low consumer and total surplus in the long run. The broader Definitions 1 and 2 eliminate many more such equilibria than the narrower Definition 3. Along with the predation-like behavior, a fair amount of competition for the market is, however, eliminated.

\footnotetext{
${ }^{27}$ See Case B in Figure 1 in Borkovsky, Doraszelski, and Kryukov (2010) for an example of such a return.
} 
Table 4-Eliminated and Surviving Equilibria for Definitions 1-3

\begin{tabular}{|c|c|c|c|c|c|c|c|c|c|c|}
\hline & & \multicolumn{3}{|c|}{$(\rho, \sigma)$} & \multicolumn{3}{|c|}{$(\rho, \bar{X})$} & \multicolumn{3}{|c|}{$(\sigma, \bar{X})$} \\
\hline & & SRP & DCV & REX & SRP & DCV & REX & SRP & DCV & REX \\
\hline & & 1 & 2 & 3 & 1 & 2 & 3 & 1 & 2 & 3 \\
\hline & elim. & $98 \%$ & $96 \%$ & $49 \%$ & $97 \%$ & $96 \%$ & $61 \%$ & $97 \%$ & $97 \%$ & $69 \%$ \\
\hline & surv. & $1 \%$ & $1 \%$ & $23 \%$ & $3 \%$ & $3 \%$ & $15 \%$ & $2 \%$ & $2 \%$ & $14 \%$ \\
\hline \multirow[t]{2}{*}{$H H I^{\infty}$} & elim. & $\begin{array}{c}0.95 \\
(0.11)\end{array}$ & $\begin{array}{c}0.95 \\
(0.11)\end{array}$ & $\begin{array}{c}0.97 \\
(0.08)\end{array}$ & $\begin{array}{c}0.87 \\
(0.12)\end{array}$ & $\begin{array}{c}0.87 \\
(0.12)\end{array}$ & $\begin{array}{c}0.88 \\
(0.11)\end{array}$ & $\begin{array}{c}0.93 \\
(0.10)\end{array}$ & $\begin{array}{c}0.93 \\
(0.10)\end{array}$ & $\begin{array}{c}0.94 \\
(0.09)\end{array}$ \\
\hline & surv. & $\begin{array}{c}0.81 \\
(0.24)\end{array}$ & $\begin{array}{c}0.80 \\
(0.24)\end{array}$ & $\begin{array}{c}0.87 \\
(0.19)\end{array}$ & $\begin{array}{c}0.54 \\
(0.13)\end{array}$ & $\begin{array}{c}0.54 \\
(0.13)\end{array}$ & $\begin{array}{c}0.78 \\
(0.20)\end{array}$ & $\begin{array}{c}0.82 \\
(0.22)\end{array}$ & $\begin{array}{c}0.81 \\
(0.22)\end{array}$ & $\begin{array}{c}0.87 \\
(0.18)\end{array}$ \\
\hline \multirow[t]{2}{*}{$\bar{p}^{\infty}$} & elim. & $\begin{array}{c}7.95 \\
(1.38)\end{array}$ & $\begin{array}{c}7.96 \\
(1.38)\end{array}$ & $\begin{array}{c}8.23 \\
(1.25)\end{array}$ & $\begin{array}{c}6.64 \\
(1.64)\end{array}$ & $\begin{array}{c}6.63 \\
(1.64)\end{array}$ & $\begin{array}{c}6.65 \\
(1.70)\end{array}$ & $\begin{array}{c}8.23 \\
(0.78)\end{array}$ & $\begin{array}{c}8.24 \\
(0.78)\end{array}$ & $\begin{array}{c}8.30 \\
(0.67)\end{array}$ \\
\hline & surv. & $\begin{array}{c}6.43 \\
(3.01)\end{array}$ & $\begin{array}{c}6.28 \\
(3.04)\end{array}$ & $\begin{array}{c}7.03 \\
(2.35)\end{array}$ & $\begin{array}{c}3.42 \\
(1.91)\end{array}$ & $\begin{array}{c}3.41 \\
(1.92)\end{array}$ & $\begin{array}{c}5.89 \\
(2.20)\end{array}$ & $\begin{array}{c}7.57 \\
(1.50)\end{array}$ & $\begin{array}{c}7.54 \\
(1.49)\end{array}$ & $\begin{array}{c}7.91 \\
(1.21)\end{array}$ \\
\hline \multirow[t]{2}{*}{$C S^{\infty}$} & elim. & $\begin{array}{c}2.19 \\
(1.50)\end{array}$ & $\begin{array}{c}2.18 \\
(1.50)\end{array}$ & $\begin{array}{c}1.87 \\
(1.33)\end{array}$ & $\begin{array}{c}3.65 \\
(1.73)\end{array}$ & $\begin{array}{c}3.65 \\
(1.73)\end{array}$ & $\begin{array}{c}3.63 \\
(1.79)\end{array}$ & $\begin{array}{l}1.98 \\
(0.94)\end{array}$ & $\begin{array}{c}1.97 \\
(0.94)\end{array}$ & $\begin{array}{c}1.91 \\
(0.82)\end{array}$ \\
\hline & surv. & $\begin{array}{c}3.86 \\
(3.30)\end{array}$ & $\begin{array}{c}4.03 \\
(3.34)\end{array}$ & $\begin{array}{c}3.19 \\
(2.58)\end{array}$ & $\begin{array}{c}7.23 \\
(2.01)\end{array}$ & $\begin{array}{c}7.24 \\
(2.02)\end{array}$ & $\begin{array}{c}4.50 \\
(2.38)\end{array}$ & $\begin{array}{c}2.76 \\
(1.81)\end{array}$ & $\begin{array}{c}2.80 \\
(1.80)\end{array}$ & $\begin{array}{c}2.36 \\
(1.47)\end{array}$ \\
\hline \multirow[t]{2}{*}{$T S^{\infty}$} & elim. & $\begin{array}{c}8.21 \\
(1.80)\end{array}$ & $\begin{array}{c}8.20 \\
(1.82)\end{array}$ & $\begin{array}{c}8.13 \\
(1.85)\end{array}$ & $\begin{array}{c}8.77 \\
(1.38)\end{array}$ & $\begin{array}{c}8.78 \\
(1.38)\end{array}$ & $\begin{array}{c}8.76 \\
(1.43)\end{array}$ & $\begin{array}{c}6.59 \\
(0.41)\end{array}$ & $\begin{array}{c}6.59 \\
(0.41)\end{array}$ & $\begin{array}{c}6.58 \\
(0.40)\end{array}$ \\
\hline & surv. & $\begin{array}{c}8.66 \\
(2.05)\end{array}$ & $\begin{array}{c}8.71 \\
(2.06)\end{array}$ & $\begin{array}{c}8.40 \\
(1.93)\end{array}$ & $\begin{array}{c}9.55 \\
(1.44)\end{array}$ & $\begin{array}{c}9.58 \\
(1.43)\end{array}$ & $\begin{array}{c}9.02 \\
(1.41)\end{array}$ & $\begin{array}{c}6.84 \\
(0.55)\end{array}$ & $\begin{array}{c}6.83 \\
(0.55)\end{array}$ & $\begin{array}{c}6.72 \\
(0.51)\end{array}$ \\
\hline \multirow[t]{2}{*}{$C S^{N P V}$} & elim. & $\begin{array}{l}152.05 \\
(38.51)\end{array}$ & $\begin{array}{l}151.91 \\
(39.02)\end{array}$ & $\begin{array}{l}151.15 \\
(39.47)\end{array}$ & $\begin{array}{l}152.61 \\
(31.39)\end{array}$ & $\begin{array}{l}152.62 \\
(31.39)\end{array}$ & $\begin{array}{l}151.55 \\
(31.76)\end{array}$ & $\begin{array}{r}105.07 \\
(4.97)\end{array}$ & $\begin{array}{c}105.05 \\
(4.96)\end{array}$ & $\begin{array}{r}104.57 \\
(4.85)\end{array}$ \\
\hline & surv. & $\begin{array}{l}152.95 \\
(38.98)\end{array}$ & $\begin{array}{l}153.78 \\
(39.16)\end{array}$ & $\begin{array}{l}151.13 \\
(38.80)\end{array}$ & $\begin{array}{l}155.43 \\
(30.62)\end{array}$ & $\begin{array}{l}156.00 \\
(30.43)\end{array}$ & $\begin{array}{l}153.08 \\
(30.92)\end{array}$ & $\begin{array}{r}106.25 \\
(4.16)\end{array}$ & $\begin{array}{r}106.08 \\
(3.96)\end{array}$ & $\begin{array}{r}105.55 \\
(4.60)\end{array}$ \\
\hline \multirow[t]{2}{*}{$T S^{N P V}$} & elim. & $\begin{array}{l}157.85 \\
(38.67)\end{array}$ & $\begin{array}{l}157.70 \\
(39.18)\end{array}$ & $\begin{array}{l}156.72 \\
(39.67)\end{array}$ & $\begin{array}{l}168.43 \\
(31.32)\end{array}$ & $\begin{array}{l}168.44 \\
(31.31)\end{array}$ & $\begin{array}{l}168.56 \\
(31.82)\end{array}$ & $\begin{array}{r}119.28 \\
(7.77)\end{array}$ & $\begin{array}{r}119.27 \\
(7.77)\end{array}$ & $\begin{array}{r}119.36 \\
(7.81)\end{array}$ \\
\hline & surv. & $\begin{array}{l}162.16 \\
(41.15)\end{array}$ & $\begin{array}{l}163.20 \\
(41.30)\end{array}$ & $\begin{array}{l}158.97 \\
(40.02)\end{array}$ & $\begin{array}{l}173.68 \\
(32.20)\end{array}$ & $\begin{array}{l}174.29 \\
(32.05)\end{array}$ & $\begin{array}{l}170.07 \\
(31.59)\end{array}$ & $\begin{array}{r}120.14 \\
(7.01)\end{array}$ & $\begin{array}{r}119.89 \\
(6.81)\end{array}$ & $\begin{array}{r}119.61 \\
(7.39)\end{array}$ \\
\hline
\end{tabular}

Notes: Industry structure, conduct, and performance. Uniformly spaced grid $(\rho, \sigma) \in\{0.0,0.05, \ldots, 1.0\}$ $\times\{0.1,0.2, \ldots, 3.0\}$ (left panel), $(\rho, \bar{X}) \in\{0.0,0.05, \ldots, 1.0\} \times\{-1.5,-1, \ldots, 7.5\}$ (middle panel), and $(\sigma, \bar{X})$ $\in\{0.1,0.2, \ldots, 3.0\} \times\{-1.5,-1, \ldots, 7.5\}$ (right panel), limited to parameterizations with multiple equilibria. Percentages in first row do not add up if the homotopy algorithm crashed and we have been unable to deduce survival or elimination from adjacent equilibria on the solution path. Averages with standard deviations in parentheses in remaining rows.

In the presence of multiple equilibria, the underlying primitives do not suffice to tie down equilibrium behavior and industry dynamics. Which equilibrium is being played additionally depends on firms' expectations regarding the evolution of the industry (Besanko et al. 2010). Our analysis suggests that guiding these expectations toward "good" equilibria by creating a business environment in which firms anticipate that predatory pricing "does not work" (by issuing general guidelines about how allegations of predation are handled, speaking out against predation, pursuing high-profile cases, etc.) can be a powerful tool for antitrust policy.

\section{Impact of Predatory Incentives}

The elimination-survival analysis illustrates the extent to which the predatory incentives according to a particular definition are responsible for "bad" equilibria. Further quantifying the impact of the predatory incentives on the evolution of the 
Table 5-Impact of Predatory Incentives for Definitions 1-3

\begin{tabular}{|c|c|c|c|c|c|c|c|c|c|c|c|c|}
\hline & \multicolumn{4}{|c|}{$(\rho, \sigma)$} & \multicolumn{4}{|c|}{$(\rho, \bar{X})$} & \multicolumn{4}{|c|}{$(\sigma, \bar{X})$} \\
\hline & Eabm & SRP & DCV & $\begin{array}{c}\text { REX } \\
3\end{array}$ & Egbm & SRP & $\begin{array}{c}\text { DCV } \\
2\end{array}$ & $\begin{array}{c}\text { REX } \\
3\end{array}$ & Egbm & SRP & DCV & $\begin{array}{c}\text { REX } \\
3\end{array}$ \\
\hline$H H I^{\infty}$ & $\begin{array}{c}0.64 \\
(0.22)\end{array}$ & $\begin{array}{c}0.56 \\
(0.16)\end{array}$ & $\begin{array}{c}0.56 \\
(0.15)\end{array}$ & $\begin{array}{c}0.61 \\
(0.19)\end{array}$ & $\begin{array}{c}0.71 \\
(0.20)\end{array}$ & $\begin{array}{c}0.50 \\
(0.02)\end{array}$ & $\begin{array}{c}0.50 \\
(0.02)\end{array}$ & $\begin{array}{c}0.68 \\
(0.16)\end{array}$ & $\begin{array}{c}0.62 \\
(0.20)\end{array}$ & $\begin{array}{c}0.53 \\
(0.11)\end{array}$ & $\begin{array}{c}0.54 \\
(0.13)\end{array}$ & $\begin{array}{c}0.60 \\
(0.18)\end{array}$ \\
\hline $\bar{p}^{\infty}$ & $\begin{array}{c}6.71 \\
(2.58)\end{array}$ & $\begin{array}{c}5.92 \\
(2.82)\end{array}$ & $\begin{array}{c}5.89 \\
(2.82)\end{array}$ & $\begin{array}{c}6.43 \\
(2.53)\end{array}$ & $\begin{array}{c}6.13 \\
(2.65)\end{array}$ & $\begin{array}{c}4.12 \\
(2.77)\end{array}$ & $\begin{array}{c}4.12 \\
(2.77)\end{array}$ & $\begin{array}{c}5.90 \\
(2.37)\end{array}$ & $\begin{array}{c}7.26 \\
(1.05)\end{array}$ & $\begin{array}{c}6.59 \\
(1.17)\end{array}$ & $\begin{array}{c}6.70 \\
(1.18)\end{array}$ & $\begin{array}{c}7.17 \\
(1.01)\end{array}$ \\
\hline$C S^{\infty}$ & $\begin{array}{c}4.57 \\
(2.66)\end{array}$ & $\begin{array}{c}5.41 \\
(2.63)\end{array}$ & $\begin{array}{c}5.46 \\
(2.59)\end{array}$ & $\begin{array}{c}4.88 \\
(2.48)\end{array}$ & $\begin{array}{c}4.41 \\
(2.64)\end{array}$ & $\begin{array}{c}6.65 \\
(2.62)\end{array}$ & $\begin{array}{c}6.65 \\
(2.62)\end{array}$ & $\begin{array}{c}4.67 \\
(2.28)\end{array}$ & $\begin{array}{c}4.02 \\
(1.38)\end{array}$ & $\begin{array}{c}4.76 \\
(0.90)\end{array}$ & $\begin{array}{c}4.64 \\
(1.04)\end{array}$ & $\begin{array}{c}4.13 \\
(1.28)\end{array}$ \\
\hline$T S^{\infty}$ & $\begin{array}{c}8.56 \\
(2.97)\end{array}$ & $\begin{array}{c}8.77 \\
(2.98)\end{array}$ & $\begin{array}{c}8.76 \\
(3.00)\end{array}$ & $\begin{array}{c}8.61 \\
(3.00)\end{array}$ & $\begin{array}{c}8.03 \\
(2.72)\end{array}$ & $\begin{array}{c}8.52 \\
(2.88)\end{array}$ & $\begin{array}{c}8.52 \\
(2.88)\end{array}$ & $\begin{array}{c}8.14 \\
(2.74)\end{array}$ & $\begin{array}{c}7.61 \\
(0.72)\end{array}$ & $\begin{array}{c}7.76 \\
(0.51)\end{array}$ & $\begin{array}{c}7.75 \\
(0.53)\end{array}$ & $\begin{array}{c}7.64 \\
(0.69)\end{array}$ \\
\hline$C S^{N P V}$ & $\begin{array}{l}123.59 \\
(49.92)\end{array}$ & $\begin{array}{c}70.03 \\
(31.78)\end{array}$ & $\begin{array}{l}121.31 \\
(49.82)\end{array}$ & $\begin{array}{l}122.14 \\
(49.28)\end{array}$ & $\begin{array}{l}133.35 \\
(54.76)\end{array}$ & $\begin{array}{c}70.10 \\
(25.36)\end{array}$ & $\begin{array}{l}131.58 \\
(54.51)\end{array}$ & $\begin{array}{l}131.61 \\
(53.78)\end{array}$ & $\begin{array}{l}96.91 \\
(8.24)\end{array}$ & $\begin{array}{c}57.94 \\
(10.30)\end{array}$ & $\begin{array}{l}93.90 \\
(8.41)\end{array}$ & $\begin{array}{c}96.49 \\
(7.71)\end{array}$ \\
\hline$T S^{N P V}$ & $\begin{array}{l}156.54 \\
(57.38)\end{array}$ & $\begin{array}{c}142.01 \\
(51.31)\end{array}$ & $\begin{array}{l}157.60 \\
(57.92)\end{array}$ & $\begin{array}{l}156.67 \\
(57.82)\end{array}$ & $\begin{array}{l}149.82 \\
(55.04)\end{array}$ & $\begin{array}{l}135.68 \\
(50.42)\end{array}$ & $\begin{array}{l}151.36 \\
(56.03)\end{array}$ & $\begin{array}{l}150.52 \\
(55.33)\end{array}$ & $\begin{array}{c}128.03 \\
(8.57)\end{array}$ & $\begin{array}{c}113.14 \\
(6.41)\end{array}$ & $\begin{array}{c}127.48 \\
(7.65)\end{array}$ & $\begin{array}{r}128.11 \\
(8.43)\end{array}$ \\
\hline
\end{tabular}

Notes: Industry structure, conduct, and performance. Uniformly spaced grid $(\rho, \sigma) \in\{0.0,0.05, \ldots, 1.0\}$ $\times\{0.1,0.2, \ldots, 3.0\}$ (left panel), $(\rho, \bar{X}) \in\{0.0,0.05, \ldots, 1.0\} \times\{-1.5,-1, \ldots, 7.5\}$ (middle panel), and $(\sigma, \bar{X})$ $\in\{0.1,0.2, \ldots, 3.0\} \times\{-1.5,-1, \ldots, 7.5\}$ (right panel). Averages with standard deviations in parentheses.

industry requires directly comparing counterfactuals to equilibria. The multiplicity of counterfactuals and equilibria makes such a comparison difficult: which counterfactual should be compared to which equilibrium?

Positing an out-of-equilibrium process by which agents adjust to a shock to the system is beyond the scope of this paper. To nevertheless get some indication of what might happen when firms are forced to ignore the predatory incentives in setting their prices, Table 5 reports side-by-side the SCP metrics for equilibria and counterfactuals. Similar to Table 4, Table 5 reports averages and standard deviations that equally weigh parameterizations.

On average, the counterfactuals have lower concentration and prices and higher consumer and total surplus in the long run than the equilibria. As a consequence of restricted competition for the market, the counterfactuals also have lower discounted consumer surplus than the equilibria. The differences between counterfactuals and equilibria are more pronounced for the broader Definitions 1 and 2 that eliminate many more aggressive equilibria than for the narrower Definition 3. Overall, Table 5 highlights that antitrust authorities may face a tension between making future consumers better off and current consumers worse off.

Table 5 further shows that $C S^{N P V}$ and-to a lesser extent-also $T S^{N P V}$ are, on average, much lower for the counterfactuals under Definition 1 than for the equilibria. By shutting down the advantage-building motive Definition 1 denies the efficiency gains from pricing aggressively in order to move down the learning curve. It further annihilates the intensive competition for the market in the well of an aggressive equilibrium. It thus tends to "throw the baby" (pricing aggressively to pursue efficiency) "out with the bath water" (predation-like behavior in aggressive equilibria).

While the averages in Table 5 provide a "broad brush" view of the impact of the predatory incentives on the evolution of the industry, the standard deviations indicate that this impact can differ depending on the parameterization. For example, forcing firms to ignore the predatory incentives in setting their prices according to Definition 3 tends to improve the SCP metrics for the baseline parameterization with $\rho=0.75$ and to worsen them for $\rho=0.7$. In this respect, our analysis echoes the 
point made by Cabral and Riordan (1997) and Farrell and Katz (2005) that, depending on the details, predatory pricing can either harm or benefit consumers. Hence, a more "scalpel-like" approach to analyzing predatory incentives may be warranted that, ideally, starts with tailoring the model to the institutional realities of the industry under study and then estimates the underlying primitives.

\section{Conclusions}

In this paper we formally characterize predatory pricing in a modern industry-dynamics framework. Our dynamic pricing model endogenizes competitive advantage and industry structure. It gives rise to an advantage-building and an advantage-denying motive under fairly general conditions that encompass learning-by-doing, network effects, switching costs, and much more. We separate a firm's incentives for pricing aggressively to eliminate competitors from the pursuit of efficiency by decomposing the equilibrium pricing condition.

We depart from the existing literature on predation in two key aspects. First, rather than aiming for an ironclad definition of predation, we decompose the equilibrium pricing condition to define a firm's predatory pricing incentives in a variety of ways. Second, rather than argue for (or against) the merits of a particular definition of predation on conceptual grounds, we directly measure the impact of the predatory incentives (according to the various definitions) on industry structure, conduct, and performance.

As an illustrative example we numerically analyze a model of learning-by-doing. Behavior resembling conventional notions of predatory pricing-aggressive pricing followed by reduced competition - arises routinely. This casts doubt on the notion that predatory pricing is a myth and does not have to be taken seriously by antitrust authorities.

Aggressive equilibria involving predation-like behavior often coexist with accommodative equilibria involving much less aggressive pricing. Multiple equilibria arise in our model if, for given demand and cost fundamentals, there is more than one set of firms' expectations regarding the value of continued play that is consistent with rational expectations about equilibrium behavior and industry dynamics. Forcing firms to ignore the predatory incentives in setting their prices can short-circuit the expectation that predatory pricing "works," and, in this way, it can eliminate some — or even all — of the aggressive equilibria. The broader Definitions 1 and 2 of predatory incentives eliminate many more equilibria than the narrower Definition 3. Along with the predation-like behavior in the aggressive equilibria, a fair amount of competition for the market is, however, eliminated.

Our analysis affords some broad conclusions. First, by viewing a dynamic world from the vantage point of a static model of profit maximization, Definition 1 annihilates competition for the market and is thus very costly for consumers and society in the short run. As it is closely related to Definition 1, this likely carries over to the classic Areeda and Turner (1975) test that equates predatory pricing with below-cost pricing. Antitrust policy based on a static model of profit maximization is likely to be "too hawkish" (Edlin and Farrell 2004, p. 502) if firms pursue efficiency on a learning curve or face other intertemporal trade-offs and may put an end to the competition for long-run advantage that leads to favorable deals for consumers. 
Second, because a fair amount of competition for the market is eliminated along with the predation-like behavior, antitrust authorities may face a tension between making future consumers better off and making current consumers worse off. This tension resonates with Judge (now US Supreme Court Justice) Stephen Breyer's "bird-in-hand" view of predatory pricing: "[T] he antitrust laws rarely reject such beneficial 'birds in hand' [an immediate price cut] for the sake of more speculative 'birds in the bush' [preventing exit and thus preventing increases in price in the future]." 28 By isolating the elements of pricing behavior that are aimed at impeding a rival's pursuit of efficiency (Definition 2) or viability (Definition 3), we provide an analytical foundation for how antitrust authorities may navigate this tension so as to strike a balance between the notion that any deviation from short-run profit maximization is predatory and the presumption that any aggressive pricing that arises as part of competition for long-run advantage is legitimate.

\section{REFERENCES}

Areeda, Phillip, and Donald F. Turner. 1975. "Predatory Pricing and Related Practices under Section 2 of the Sherman Act." Harvard Law Review 88 (4): 697-733.

Argote, Linda, Sara L. Beckman, and Dennis Epple. 1990. "The Persistence and Transfer of Learning in an Industrial Setting." Management Science 36 (2): 140-54.

Baker, Jonathan B. 1994. "Predatory Pricing after Brooke Group: An Economic Perspective." Antitrust Law Journal 62 (3): 585-603.

Başar, Tamer, and Geert Jan Olsder. 1999. Dynamic Noncooperative Game Theory, 2nd ed. Philadelphia: Society for Industrial and Applied Mathematics.

Benkard, C. Lanier. 2000. "Learning and Forgetting: The Dynamics of Aircraft Production." American Economic Review 90 (4): 1034-54.

-Bergemann, Dirk, and Juuso Valimaki. 1996. “Learning and Strategic Pricing." Econometrica 64 (5): $1125-49$.

-Bergemann, Dirk, and Juuso Valimaki. 2006. "Dynamic Price Competition.” Journal of Economic Theory 127 (1): 232-63.

-Besanko, David, Ulrich Doraszelski, Yaroslav Kryukov, and Mark Satterthwaite. 2010. "Learning-by-Doing, Organizational Forgetting, and Industry Dynamics." Econometrica 78 (2): 453-508.

Bolton, Patrick, Joseph F. Brodley, and Michael H. Riordan. 2000. "Predatory Pricing: Strategic Theory and Legal Policy.” Georgetown Law Journal 88 (8): 2239-2330.

Bolton, Patrick, and David S. Scharfstein. 1990. "A Theory of Predation Based on Agency Problems in Financial Contracting." American Economic Review 80 (1): 93-106.

Bork, Robert H. 1978. The Antitrust Paradox. New York: Free Press.

Borkovsky, Ron N., Ulrich Doraszelski, and Yaroslav Kryukov. 2010. “A User's Guide to Solving Dynamic Stochastic Games Using the Homotopy Method.” Operations Research 58 (4): 1116-32.

Borkovsky, Ron N., Ulrich Doraszelski, and Yaroslav Kryukov. 2012. "A Dynamic Quality Ladder Model with Entry and Exit: Exploring the Equilibrium Correspondence Using the Homotopy Method." Quantitative Marketing and Economics 10 (2): 197-229.

Cabral, Luís. 2011. "Dynamic Price Competition with Network Effects." Review of Economic Studies $78(1)$ : 83-111.

Cabral, Luís, and Michael H. Riordan. 1994. "The Learning Curve, Market Dominance, and Predatory Pricing." Econometrica 62 (5), 1115-40.

Cabral, Luís M. B., and Michael H. Riordan. 1997. “The Learning Curve, Predation, Antitrust, and Welfare.' Journal of Industrial Economics 45 (2): 155-69.

Caves, R. E., and M. E. Porter. 1977. "From Entry Barriers to Mobility Barriers: Conjectural Decisions and Contrived Deterrence to New Competition." Quarterly Journal of Economics 91 (2): 241-61.

Chen, Jiawei. 2011. "How Do Switching Costs Affect Market Concentration and Prices in Network Industries?" Unpublished. 
Chen, Jiawei, Ulrich Doraszelski, and Joseph E. Harrington Jr. 2009. "Avoiding Market Dominance: Product Compatibility in Markets with Network Effects." RAND Journal of Economics 40 (3): 455-85.

Ching, Andrew T. 2010. "A Dynamic Oligopoly Structural Model for the Prescription Drug Market after Patient Expiration.” International Economic Review 51 (4): 1175-1207.

Darr, Eric D., Linda Argote, and Dennis Epple. 1995. “The Acquisition, Transfer, and Depreciation of Knowledge in Service Organizations: Productivity in Franchises." Management Science 41 (11): $1750-62$.

Dick, Andrew R. 1991. "Learning by Doing and Dumping in the Semiconductor Industry." Journal of Law and Economics 34 (1): 133-59.

Doraszelski, Ulrich, and Mark Satterthwaite. 2010. "Computable Markov-Perfect Industry Dynamics." RAND Journal of Economics 41 (2): 215-43.

Dube, Jean-Pierre H., Gunter J. Hitsch, and Pradeep K. Chintagunta. 2010. “Tipping and Concentration in Markets with Indirect Network Effects.” Marketing Science 29 (2): 216-49.

Dube, Jean-Pierre, Gunter J. Hitsch, and Peter E. Rossi. 2009. "Do Switching Costs Make Markets Less Competitive?" Journal of Marketing Research 46 (4): 435-45.

-Edlin, Aaron S. 2002. "Stopping Above-Cost Predatory Pricing." Yale Law Journal 111 (4): 941-91.

Edlin, Aaron S. 2012. "Predatory Pricing.” In Research Handbook on the Economics of Antitrust Law, edited by Einer Elhauge, 144-73. Northampton, MA: Edward Elgar Publishing, Inc.

Edlin, Aaron S., and Joseph Farrell. 2004. "The American Airlines Case: A Chance to Clarify Predation Policy (2001)." In The Antitrust Revolution: Economics, Competition, and Policy, edited by John E. Kwoka Jr. and Lawrence J. White, 502-27. New York: Oxford University Press.

Erdem, Tulin, Susumu Imai, and Michael P. Keane. 2003. "Brand and Quantity Choice Dynamics under Price Uncertainty." Quantitative Marketing and Economics 1 (1): 5-64.

Ericson, Richard, and Ariel Pakes. 1995. "Markov-Perfect Industry Dynamics: A Framework for Empirical Work.” Review of Economic Studies 62 (1): 53-82.

-Farrell, Joseph, and Michael L. Katz. 2005. "Competition or Predation? Consumer Coordination, Strategic Pricing and Price Floors in Network Markets." Journal of Industrial Economics 53 (2): 203-31.

Filar, Jerzy, and Koos Vrieze. 1997. Competitive Markov Decision Processes. New York: Springer.

-Flamm, Kenneth. 1993. "Semiconductor Dependency and Strategic Trade Policy." Brookings Papers on Economic Activity: Microeconomics 1: 249-333.

Flamm, Kenneth. 1996. Mismanaged Trade? Strategic Policy in the Semiconductor Industry. Washington, DC: Brookings Institution Press.

-Fudenberg, Drew, and Jean Tirole. 1986. “A 'Signal-Jamming' Theory of Predation.” RAND Journal of Economics 17 (3): 366-76.

-Goettler, Ronald L., and Brett R. Gordon. 2011. “Does AMD Spur Intel to Innovate More?” Journal of Political Economy 119 (6): 1141-1200.

Gowrisankaran, Gautam, and Marc Rysman. 2012. "Dynamics of Consumer Demand for New Durable Goods." Journal of Political Economy 120 (6): 1173-1219.

Hendel, Igal, and Aviv Nevo. 2006. "Measuring the Implications of Sales and Consumer Inventory Behavior." Econometrica 74 (6): 1637-73.

Jørgensen, Steffen, and Georges Zaccour. 2004. Differential Games in Marketing. Dordrecht: Kluwer Academic Publishers.

-Jun, Byoung, and Xavier Vives. 2004. "Strategic Incentives in Dynamic Duopoly." Journal of Economic Theory 116 (2): 249-81.

Kreps, David M., and Robert Wilson. 1982. "Reputation and Imperfect Information.” Journal of Economic Theory 27 (2): 253-79.

-Lapham, Beverly, and Roger Ware. 1994. "Markov Puppy Dogs and Related Animals." International Journal of Industrial Organization 12 (4): 569-93.

Mitchell, Matthew F., and Andrzej Skrzypacz. 2006. "Network Externalities and Long-Run Market Shares." Economic Theory 29 (3): 621-48.

Ordover, Janusz, and Garth Saloner. 1989. "Predation, Monopolization, and Antitrust.” In Handbook of Industrial Organization, Vol. 1, edited by Richard Schmalensee and Robert D. Willig, 537-96. Amsterdam: North-Holland.

Ordover, Janusz A., and Robert D. Willig. 1981. “An Economic Definition of Predation: Pricing and Product Innovation." Yale Law Journal 91 (1): 8-53.

Shafer, Scott M., David A. Nembhard, and Mustafa V. Uzumeri. 2001. "The Effects of Worker Learning, Forgetting, and Heterogeneity on Assembly Line Productivity.” Management Science 47 (12): 1639-53.

Shalem, Roy, Yossi Spiegel, and Konrad Stahl. 2011. “A Dynamic Model of Predation.” Unpublished. 
Snider, Connan. 2008. "Predatory Incentives and Predation Policy: The American Airlines Case." Unpublished.

Stigler, G. J. 1950. "Monopoly and Oligopoly by Merger." American Economic Review 40 (2): 23-34.

- Thompson, Peter. 2007. "How Much Did the Liberty Shipbuilders Forget?" Management Science 53 (6): 908-18.

Willig, Robert D., Jonathan M. Orszag, and Gilad Levin. 2009. An Economic Perspective on the Antitrust Case Against Intel. Technical Report, Compass Lexecon.

Yamamura, Kozo, and Jan Vandenberg. 1986. "Japan's Rapid-Growth Policy on Trial: The Television Case." In Law and Trade Issues of the Japanese Economy: American and Japanese Perspectives, edited by Gary R. Saxonhouse and Kozo Yamamura, 238-83. Seattle: University of Washington Press. 